\title{
Recent progress in direct patterning technologies based on nano-imprint lithography
}

\author{
K.-J. Byeon and H. Lee ${ }^{\mathrm{a}}$ \\ Department of Materials Science and Engineering, Korea University, 5-1 Anam-dong, Sungbuk-gu, \\ Seoul, 136-713, South Korea
}

Received: 30 April 2012 / Received in final form: 27 June 2012 / Accepted: 2 July 2012 Published online: 3 August 2012 - (c) The Author(s) 2012

\begin{abstract}
Nano-imprint lithography (NIL) is one of the most promising patterning technologies, in which nano- and micro-patterns are fabricated on various substrates. NIL provides high throughput and low cost in fabricating nano-structures due to its simple process and allows resolution below $10 \mathrm{~nm}$ without issues of light diffraction with conventional lithographic techniques. Its patterning mechanism is based on mechanical deformation of a polymer resist, which is simply done by pressing with a mold. This patterning mechanism also enables inorganic and organic-inorganic hybrid materials to be directly patterned by NIL. This article covers the recent progress of NIL-based direct patterning techniques and their applications to devices. Recently, functional nano- and micro-patterns have been applied to various electronic devices for the enhancement of overall performance. Fabrication methods of these devices are difficult using conventional lithographic techniques due to complex processes, high cost and low throughput. Direct NIL technique using functional resist can simply fabricate functional nano- and micro-structures and thus can be usefully applied to various industries.
\end{abstract}

\section{Introduction}

With recent development in electronic devices in various fields including printable electronics, light-emitting diodes (LEDs), organic LEDs (OLEDs), thin film solar cells, organic solar cells and organic thin film transistors, the fabrication of functional nano-structures has become increasingly important to enhance the overall performance of various devices. In the semiconductor industry, the capability of fabricating precisely aligned nano-patterns with high resolution is very significant for producing highly integrated circuits and smaller transistors. DeepUV photolithography [1-3] has been optimized for the semiconductor industry as a main patterning technology. However, it is difficult to adopt photolithography for various next-generation electronic devices due to its high process cost, complex process steps and limitation on the use of substrates.

Recently, various nano-patterning techniques, such as laser interference lithography [4-6], nano-sphere lithography [7-9], block copolymer lithography [10-12], nanoimprint lithography (NIL) [13-20], have been developed in order to fabricate nano-patterns with low process cost. Conventionally, to fabricate nano-patterns composed of inorganic functional materials via these indirect patterning techniques, four common steps are needed, including deposition of functional materials, formation of polymer resist patterns on the functional material layer, descum of

\footnotetext{
a e-mail: heonlee@korea.ac.kr
}

polymer resist patterns and dry or wet etching of functional materials. However, these patterning methods have some drawbacks, such as complex process, waste of materials, long process time and substrate damage, induced by the etch process. To overcome these problems, many studies on direct nano-patterning techniques of functional materials have been conducted, such as dip-pen lithography [21-23], gravure offset printing [24-26], ink-jet lithography [27-29], and so on. These patterning techniques can directly fabricate nano-patterns composed of functional materials. However, it is difficult to apply these direct nano-patterning techniques to various electronic devices due to their limitations such as low throughput, lack of capability for large area patterning and low resolution.

NIL has been noted as one of the most promising nextgeneration patterning techniques due to its high throughput, high resolution (sub-10 $\mathrm{nm}[30,31]$ ) and low cost. It has the capability to directly fabricate inorganic or organic-inorganic hybrid nano-patterns because the patterning mechanism of NIL is based on the physical contact between a mold and a resist. In this paper, we discuss NILbased direct patterning processes using various functional resists and their applications.

\section{Principle and types of NIL process}

Figure 1a is a schematic diagram of the NIL process which was initially developed by Chou's group [13]. A thermoplastic polymer resin such as poly(methyl methacrylate) 
(a)
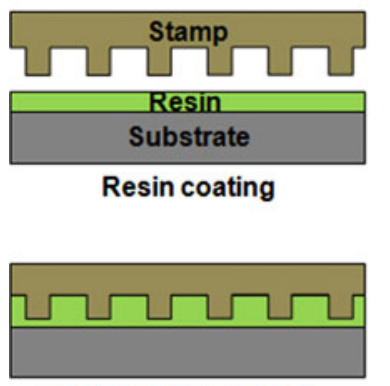

Heating and pressing
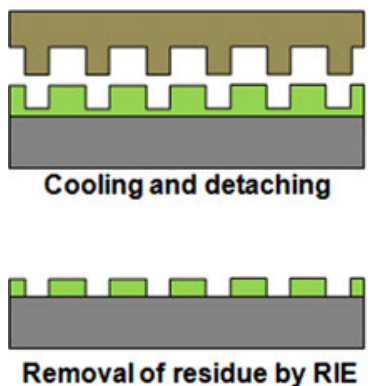

(b)
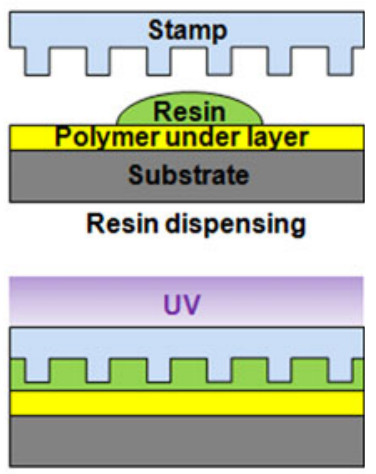

Pressing and UV exposure

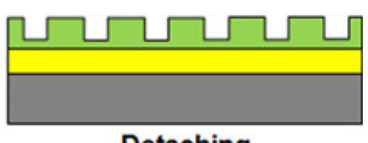

Detaching

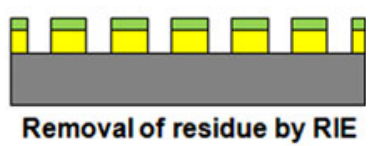

Fig. 1. (Color online) Schematic diagrams of (a) NIL and (b) S-FIL.

(PMMA) is coated on a substrate and is physically pressed by an imprinting stamp with a protrusion pattern at a temperature above the glass transition temperature $\left(T_{g}\right)$ of the polymer resin with high pressure $\left(>5 \times 10^{6} \mathrm{~Pa}\right)$. After the imprinting process, the stack of the stamp and the substrate with the coated polymer layer is cooled down to a temperature below $T_{g}$ of the polymer resin and then the stamp is detached from the polymer resin/substrate. Through these procedures, the imprinted polymer pattern with negative phase of the imprinting stamp can be formed on the substrate. After the imprinting process, the residual layer is cleared off by reactive ion etching (RIE) and the imprinted pattern is used as an etching mask of the substrate or deposition mask for a lift-off process.

Willson's group developed step-and-flash imprint lithography (S-FIL), which has the capability to fabricate nano-patterns at room temperature and at low pressure (Fig. 1b) [14]. In the S-FIL process, a UV photo-curable liquid phase resist, based on monomer or oligomer, is used as the imprinting resin. The liquid phase resist can be easily filled into the cavity of the stamp during the imprinting because of its low viscosity at a very low imprinting pressure $\left(<1 \times 10^{5} \mathrm{~Pa}\right)$. When holding the pressure, the imprint resin is exposed to UV light through a transparent template, and then the imprint resin can be cured rapidly by the cross-linking of the monomer or oligomer for polymerization. Due to its capability to form nanopatterns at room temperature and low pressure, the template can be stepped to fabricate nano-patterns on entire wafers using stepper lithographic equipment. Similar to S-FIL, thermoset NIL using a monomer- or oligomer-based resist containing a thermal initiator has been developed by
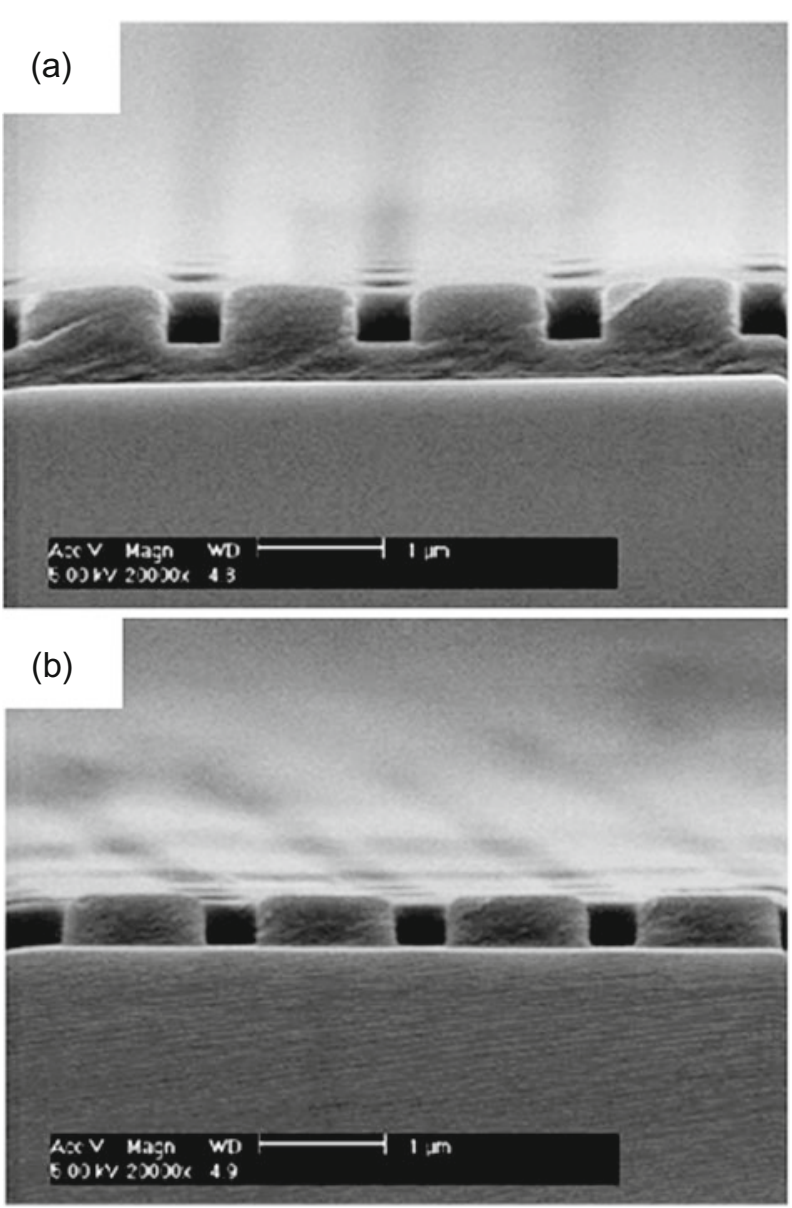

Fig. 2. (a) Cross-sectional SEM picture of imprinted resin with uniform, but thick residual layer. (b) Imprinted resin with near zero-residual layer. Both are imprinted by the same stamp. Reproduced with permission from reference [15]. Copyright 2004, Elsevier.

many research groups. The thermoset NIL process is same as the UV NIL process, except that the imprint resin is cured by heat instead of UV.

These NIL processes using monomer- or oligomerbased resin enable fabrication of near zero-residual imprint patterns [15,32-38]. Figures $2 \mathrm{a}$ and 2b are scanning electron microscope (SEM) micrographs of the UV-imprinted patterns made by our group with benzylmethacrylate monomer at pressures of 5 atm and 20 atm, respectively [15]. In order to achieve uniform patterns with near zero residue, a sufficient amount of resin with high fluidity should be dispensed on a substrate to ensure no local deficiency of resin, and a sufficient imprinting pressure is required to squeeze the excess resin toward the outside of the substrate, as shown in Figure 2.

\section{NIL-based direct patterning processes}

\subsection{NIL processes using the deformation of inorganic thin film}

In the NIL process, nano-sized patterns are fabricated by physical contact between the stamp and the imprinting 
resist. This patterning mechanism of NIL, which is different from those of other lithographic techniques such as photolithography, e-beam lithography and laser interference lithography, allows direct fabrication of inorganic material-based nano-structures through a single-step imprinting process and reduces the process cost and the consumption of materials. Several studies related to direct NIL of inorganic materials have been presented. In these studies, inorganic layers were patterned by the deformation of the inorganic layer at high pressure or local melting of the surface of the inorganic layer. Representative NIL processes of inorganic layers include laser-assisted direct imprint (LADI) and room temperature (RT)-NIL. LADI, proposed by Prof. Chou et al., is a direct imprinting process of Si using a quartz mold and excimer laser [39]. Figure $3 \mathrm{a}$ is a schematic diagram of the LADI process. At first, a quartz master mold is put on the Si wafer substrate. Then, an excimer laser is irradiated onto the surface of the Si wafer substrate through the quartz mold. The excimer laser locally melts the surface of the Si wafer substrate, and the melted $\mathrm{Si}$ is moved into the cavity of the quartz mold by mechanical pressing. After the LADI process, the quartz mold is detached from the substrate and the Si nano-patterns are formed on the surface of the Si wafer, as shown in Figure 3b.

RT-NIL is a technique to fabricate functional materialbased nano-structures by a simple pressing process at high pressure. RT-NIL technique is based on the deformation of the imprinted thin film by pressurization with the imprinting mold. Because most inorganic thin films have little fluidity, a high imprinting pressure above $1 \times 10^{7} \mathrm{~Pa}$ and an imprinting mold more rigid than the imprinted thin films are needed for the RT-NIL process. Figures $4 \mathrm{a}$ and $4 \mathrm{~b}$ show SEM micrographs of aluminum patterns demonstrated by our group [40], and copper patterns demonstrated by Taniguchi et al. [41], respectively. As shown in Figure 4, metal layers with a high ductility like $\mathrm{Al}$ and $\mathrm{Cu}$ were directly patterned using this RT-NIL technique. In these NIL processes, high pressure was needed to directly imprint inorganic materials. However, this harsh condition generates damage such as crack and contamination on the mold, and limits the use of various substrates. Moreover, the cost of fabricating the rigid mold is very expensive. Therefore, a direct NIL process of functional materials with low pressure and simple process should be developed for practical industrial applications.

\subsection{Process types of direct NIL using functional resists}

In recent years, functional resist-based NIL processes, including soft-NIL [42-45] and nano-transfer printing [46-50] and nano-contact printing [51-55], have been developed to directly fabricate nano-structures consisting of inorganic or organic-inorganic hybrid materials. The NIL-based direct patterning process also has advantages such as high throughput, high resolution and low cost. In addition, it can fabricate inorganic or organic-inorganic hybrid nano-patterns on various substrates and thus can be applied to diverse electronic devices to enhance the (a)

\section{a Contact mould and substrate $(t=0)$}

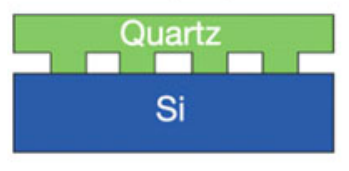

b

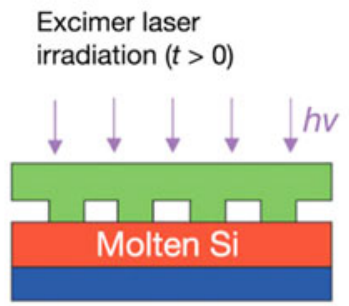

c Silicon embossing

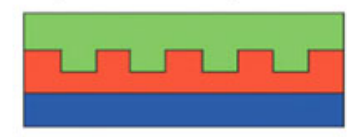

Silicon solidification ( $t>250 \mathrm{~ns})$

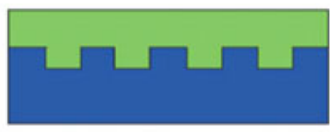

e Mould and substrate separation

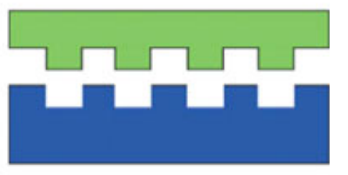
$(0<t<250 \mathrm{~ns})$

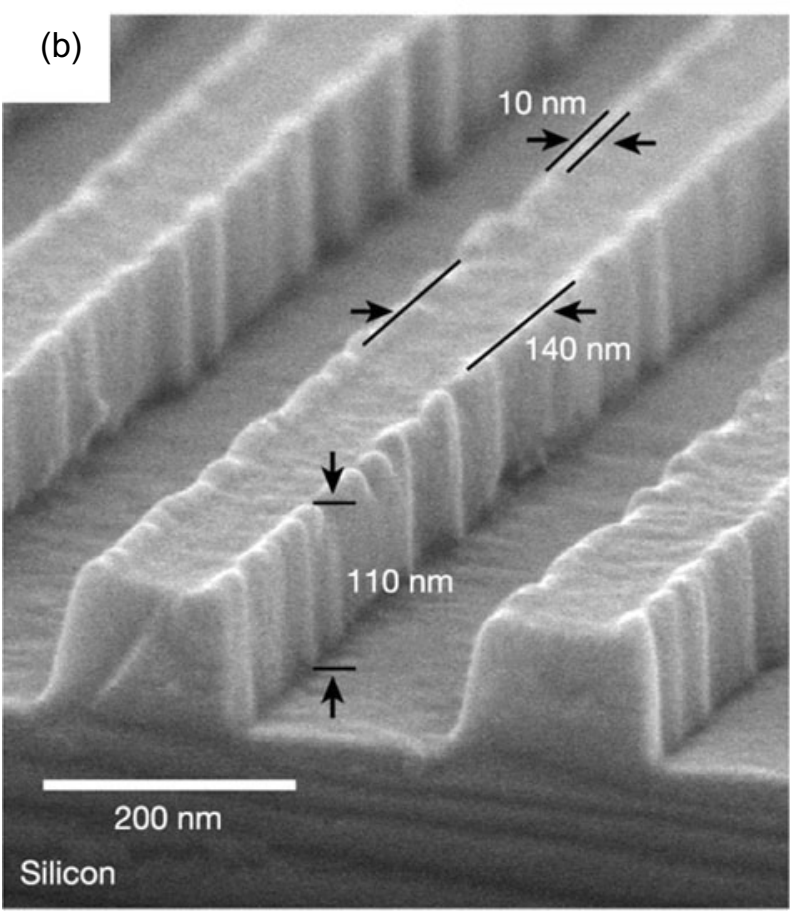

Fig. 3. (Color online) (a) Schematic diagram of the laserassisted direct imprint (LADI) process. (b) Directly formed Si nano-patterns from the LADI process. Reproduced with permission from reference [39]. Copyright 2002, Nature Publishing Group.

performance. Nano-patterns consisting of functional materials can be directly fabricated by NIL using functional resist.

Soft-NIL is a kind of NIL technique using a polymeric mold instead of a conventional rigid material-based mold, such as quartz, Si, nickel, and so on, as shown in Figure 5a. Various types of polymeric molds can be fabricated from a master template by replication process, such as hot-embossing, nano- and micro-molding [56-60]. 
(a)

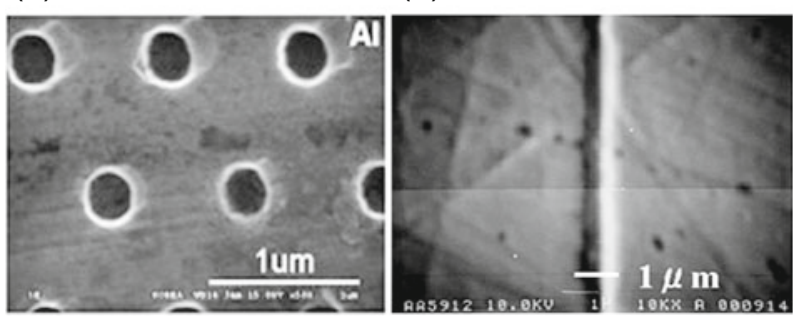

Fig. 4. SEM micrographs of directly imprinted metal patterns: (a) Aluminum pattern. Reprinted with permission from reference [40]. Copyright 2011, Springer. (b) Copper pattern. Reprinted with permission from reference [41]. Copyright 2002, Institute of Physics.

Among them, a soft polymer mold such as a poly (dimethylsiloxane) (PDMS) is very useful in the NIL process using functional resists containing organic solvents due to its high gas permeability and the capability of absorbing an organic solvent. Most of the functional resist, such as sol-gel solution [61-66], nanoparticle-dispersed solution [67-73], metal nano-ink [74-78], spin-on-glass (SOG) resist [79-82], are formulated by mixing precursors or nanoparticles in an organic solvent. To fabricate nanostructures consisting of functional materials by NIL, the solvent in the functional resist and gas products generated from hydrolysis-condensation reaction [83-86] should be removed during the NIL process. Also, the surface energy of the mold should be small enough for easy detachment between the mold and the functional resist. The mold should also be soft enough to achieve conformal contact with the substrate. According to these requirements, an elastomeric PDMS mold has been most commonly used for NIL-based patterning of functional resist. The PDMS has high permeability [87-89], so the solvent and the gas product can be removed through the PDMS mold during the NIL process. Additionally, the low surface energy [90,91] of the PDMS mold promotes uniform transferring of functional nano-patterns from the PDMS mold to the substrate without problems related to resist sticking to the mold.

Nano-printing is also one kind of NIL technique that has high throughput patterning due to its short process time and simplicity. The nano-printing process has a different patterning mechanism from conventional NIL. Since pattern transferring in the nano-printing process is conducted by the difference in the surface energy between the mold and the substrate, high pressure and high temperature are not needed for pattern transferring, and various functional resists, such as conductive polymer, nano-composite, metal ink and organic monomer resist, can be patterned, as well as conventional polymer resin. In the nano-printing process, the mold plays the most important role for pattern transferring. Conventionally, PDMS is most commonly used for mold materials due to its low surface energy $(\sim 21.6 \mathrm{dyn} / \mathrm{cm})[90,91]$ and inertness to most chemicals. If the surface energy of the mold is high and the mold material is chemically unstable, pattern transferring is very difficult because of the adhesive force between the mold and the functional resist.

The nano-printing process is divided into nano-transfer printing (reverse imprint [92-94]) and nano-contact printing. Figure 5b shows the overall process of nano-transfer printing. A functional resist is firstly coated on the mold surface. During the coating of the resist on the mold, the resist fills the protrusion pattern of the mold. After the resist coating, the resist-coated mold is pressed down on the substrate and the patterned resist layer is transferred by difference in the surface energy between the mold and the substrate, and strong adhesion between the resist and the substrate. Since defining the pattern is achieved by a simple coating process on the mold, high pressure is not required in nano-transfer printing, unlike the conventional NIL process, but controlling the residual layer is difficult. The mechanism of nano-contact printing is shown in Figure 5c. Nano-contact printing is very useful to form functional material-based nano-patterns without a residual layer. Firstly, functional molecules or inks are deposited on the surface of the mold. Secondly, the functional molecules or the inks-coated mold is placed in contact with the substrate at very low pressure and at room temperature. Only the functional molecules or the inks on the protrusion of the mold are in contact with the substrate and transferred to the substrate after detaching the mold. Although nano-contact printing allows the fabrication of zero-residual nano-patterns, it is difficult to achieve uniform pattern transferring on a large area.

\subsection{NIL processes using sol-gel solutions}

Currently, diverse inorganic materials including $\mathrm{ZnO}$, indium tin oxide (ITO), $\mathrm{TiO}_{2}, \mathrm{SiO}_{2}, \mathrm{SnO}_{2}$, Al-doped $\mathrm{ZnO}$, and so on can be fabricated by sol-gel process [61-66]. In comparison to other film deposition methods, such as sputtering, chemical vapor deposition or pulsed laser deposition, the sol-gel process has distinguishing advantages including low process cost, good compositional control and large area production. The sol-gel process can be used to fabricate inorganic materials from sol-containing inorganic or organic precursors. A sol is coated on the substrate by dip coating or spin-coating and then solid-state gel film is formed by a drying process which evaporates the solvent in the sol. Afterwards, the gel film is converted to polycrystalline inorganic film by an annealing process that promotes densification and grain growth. In recent years, sol-gel NIL has been developed to directly fabricate functional nano-patterns consisting of inorganic or organicinorganic hybrid materials.

$\mathrm{Li}$ et al. [95] reported a direct nano-imprinting process of $\mathrm{SiO}_{2}-\mathrm{TiO}_{2}$ gel film for fabricating waveguide gratings. $\mathrm{SiO}_{2}-\mathrm{TiO}_{2}$ hybrid gel film was formed on Si substrate by spin-coating a sol mixed with a tetraethoxysilane (TEOS) solution and a titanium tetrabutoxide solution and imprinting with an $\mathrm{SiO}_{2}$-based hard mold at $200{ }^{\circ} \mathrm{C}$. After the imprinting process, the imprinted gel film on the $\mathrm{Si}$ substrate was converted into patterned inorganic film consisting of gratings with $300 \mathrm{~nm}$ pitch and $80 \mathrm{~nm}$ line width 
(a)

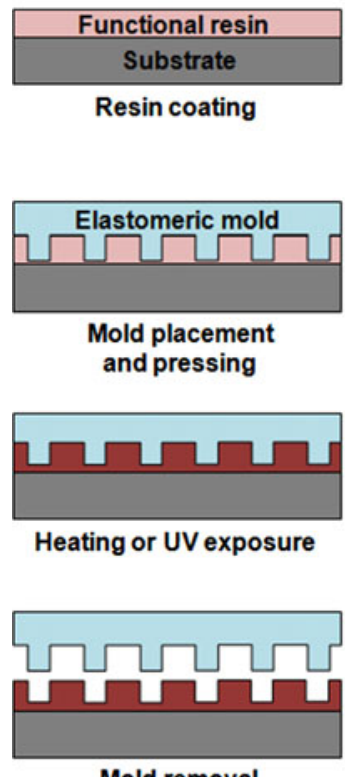

(b)
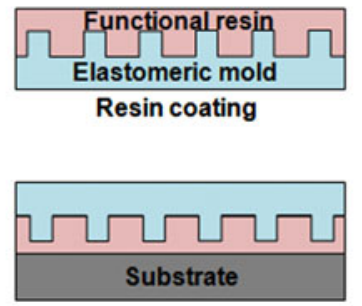

Printing on substrate

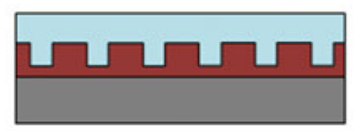

Heating or UV exposure

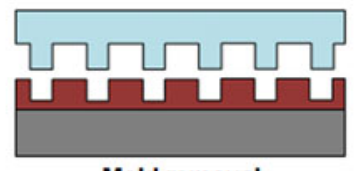

Mold removal (c)
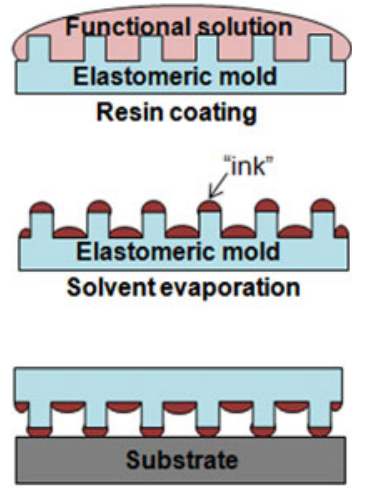

Contact the mold with

the substrate

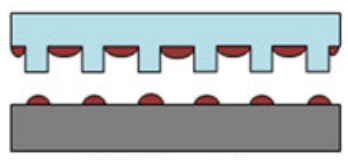

Mold removal

Fig. 5. (Color online) Schematic diagrams of (a) soft-NIL, (b) nano-transfer printing (reverse imprint) and (c) nano-contact printing using a functional resist.

by an annealing process. In their work, a functional nanoscaled pattern consisting of inorganic materials could be directly fabricated, but high imprinting pressure (645 psi) was required to imprint the high viscosity gel film.

To imprint a sol-based functional resin at a low pressure, the sol should be directly pressed with a mold before the gelation of the sol. The mold should also have high permeability to absorb the solvent in the sol during the imprinting process and low surface energy to prevent sticking of the sol to the mold. In the NIL process using a sol as an imprint resist, the sol solution is first coated on the substrate and then is imprinted with a mold with a high permeability. During the imprinting process, the cavity of the mold is filled with the sol, and extra solvent and gas products generated from hydrolysis-condensation reaction are removed by absorption into the mold. After detaching the mold from the substrate, the imprinted gel pattern can be converted to a patterned inorganic layer by annealing.

In our previous work, low pressure direct NIL using a PDMS mold and a sol containing an oxide precursor was established [96]. The procedure of the NIL process using a sol is described in Figure 6a. An ethanol-based $\mathrm{TiO}_{2}$-sol containing tetrabutylorthotitanate precursor was spin-coated onto an oxidized Si substrate, and a PDMS mold previously replicated from an $\mathrm{Si}$ master template was immediately placed on the $\mathrm{TiO}_{2}$ sol/Si substrate. Afterwards, $5 \mathrm{~atm}$ of pressure was applied to press the PDMS mold down on the sol/Si substrate at $200{ }^{\circ} \mathrm{C}$ while vacuum was maintained over the imprint chamber to remove air bubbles and promote spreading of the sol. During the NIL process, the $\mathrm{TiO}_{2}$ sol filled the cavity of the protrusion of the PDMS mold and the solvent in the $\mathrm{TiO}_{2}$ sol was moved into the PDMS mold and removed. Sequentially, the $\mathrm{TiO}_{2}$ sol was converted into the gel layer through thermal imprinting, and the patterned gel layer was formed. To transform the gel layer into an inorganic $\mathrm{TiO}_{2}$ layer, oxidized $\mathrm{Si}$ substrate with the patterned $\mathrm{TiO}_{2}$ gel layer was annealed between $400{ }^{\circ} \mathrm{C}$ and $700{ }^{\circ} \mathrm{C}$ for $1 \mathrm{~h}$ in air. As a result, the patterned $\mathrm{TiO}_{2}$ gel layer was changed to an anatase $\mathrm{TiO}_{2}$ crystalline layer between $400{ }^{\circ} \mathrm{C}$ and $600{ }^{\circ} \mathrm{C}$, and a rutile $\mathrm{TiO}_{2}$ crystalline layer at $700{ }^{\circ} \mathrm{C}$. In Figure 6b, SEM micrographs of the surface patterns of the Si master template, the imprinted $\mathrm{TiO}_{2}$ gel patterns and the polycrystalline $\mathrm{TiO}_{2}$ patterns after annealing are shown. Inorganic $\mathrm{TiO}_{2}$ material could be directly patterned to sub-micron size through the sol-gel NIL process. As shown in Figure 6b, the dimension of the crystalline $\mathrm{TiO}_{2}$ pattern was inevitably reduced by the gelation and final annealing, due to the sol-gel transition of $\mathrm{TiO}_{2}$, evaporation of the solvent, removal of organic compound and close packing at high temperature.

Although the PDMS mold has been diversely used for various soft-NIL processes, the resolution of the imprinted pattern with PDMS mold has been limited to $>100 \mathrm{~nm}$ due to its relatively low modulus ( $2 \mathrm{MPa}$ ) [97]. To achieve about $50 \mathrm{~nm}$ resolution, hard PDMS (h-PDMS) with a modulus of $\sim 9 \mathrm{MPa}$ was developed [98]. Our group fabricated various $\mathrm{ZnO}$ patterns using the h-PDMS-based sol-gel NIL process [99]. The h-PDMS mold was fabricated by two steps which include formation of thin h-PDMS layer on the master template and formation of normal PDMS support layer on the h-PDMS layer. First, toluene-based h-PDMS solution containing vinyl PDMS prepolymer, platinum divinyltetramethyldisiloxane, 2,4, 6,8-tetramethyltetravinylcyclotetrasiloxane and hydrosilane prepolymer was spin-coated on the master template and was baked at $60{ }^{\circ} \mathrm{C}$ for $1 \mathrm{~h}$. Next, the 
(a)

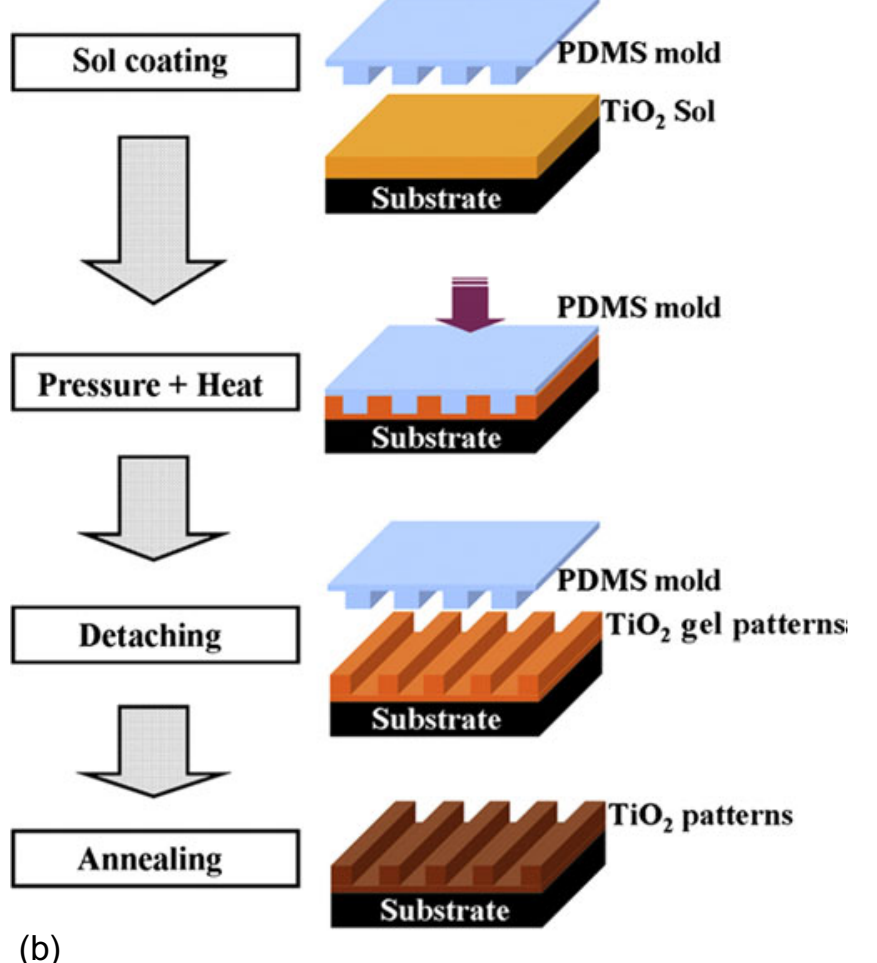

(b)
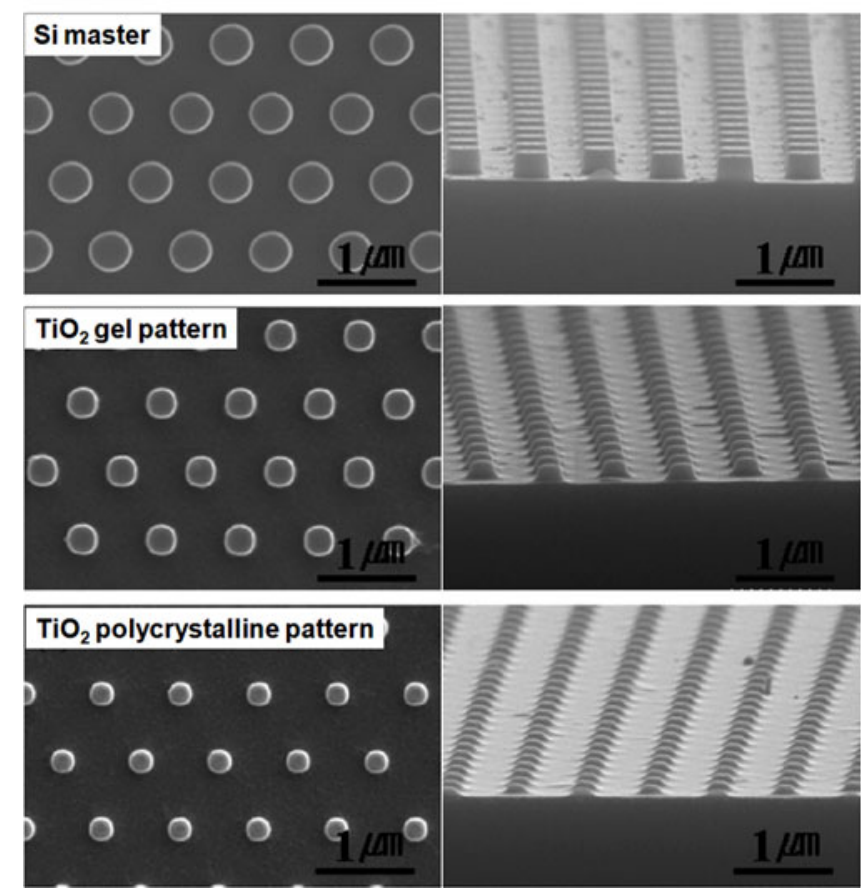

Fig. 6. (Color online) (a) A schematic diagram of $\mathrm{TiO}_{2}$ sol-based nano-imprint lithography process. (b) SEM micrographs of the Si master, the $\mathrm{TiO}_{2}$ gel pattern and the $\mathrm{TiO}_{2}$ polycrystalline pattern. Reproduced with permission from reference [96]. Copyright 2009, Elsevier.

normal PDMS solution was spin-coated on the surface of the h-PDMS layer and was baked at $80{ }^{\circ} \mathrm{C}$ for $1 \mathrm{~h}$.
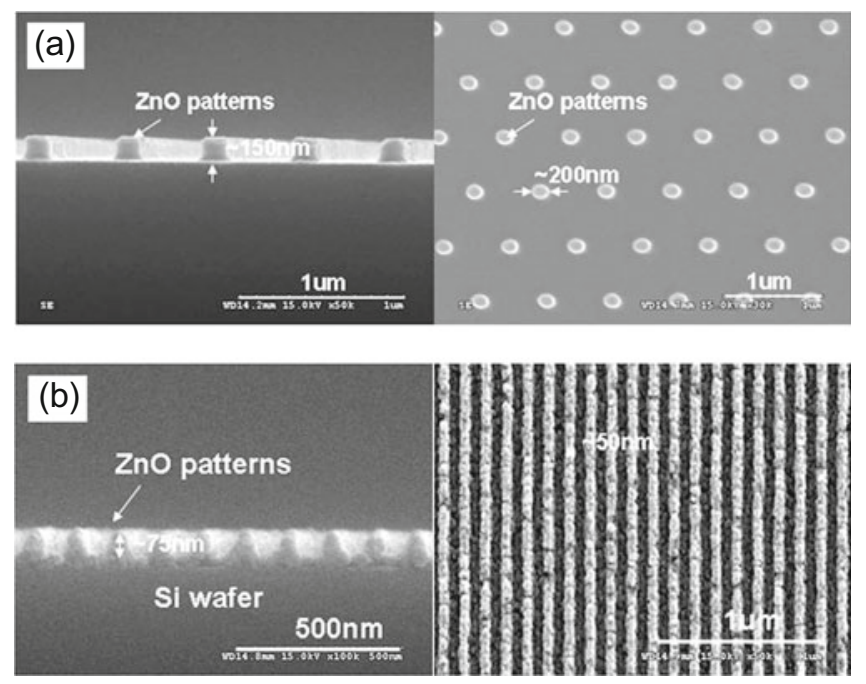

Fig. 7. SEM micrographs of (a) the ZnO pattern with $200 \mathrm{~nm}$ diameter. (b) The $\mathrm{ZnO}$ pattern with $50 \mathrm{~nm}$ line width on the Si substrate after the sol-gel NIL process and final annealing. Reproduced with permission from reference [99]. Copyright 2009, Elsevier.

Afterwards, N,N-dimethylformamide (DMF)-based ZnOsol containing zinc acetate 2-hydrate $\left(\mathrm{Zn}\left(\mathrm{CH}_{3} \mathrm{COO}\right)_{2}\right.$. $2 \mathrm{H}_{2} \mathrm{O}$ ) was spin-coated on the Si wafer substrate and thermal NIL with the h-PDMS mold was followed at $200{ }^{\circ} \mathrm{C}$ while 5 atm of pressure was maintained. Through the NIL process, the imprinted $\mathrm{ZnO}$ gel layer was formed on the Si substrate and the $\mathrm{ZnO}$ gel pattern was converted to pure inorganic $\mathrm{ZnO}$ pattern by annealing at $650{ }^{\circ} \mathrm{C}$ for $1 \mathrm{~h}$ in air ambient. This NIL process is almost the same as the $\mathrm{TiO}_{2}$ sol-gel-based NIL process mentioned above. Figures $7 \mathrm{a}$ and $7 \mathrm{~b}$ show the $\mathrm{ZnO}$ pattern with $200 \mathrm{~nm}$ diameter, and the $\mathrm{ZnO}$ pattern with $50 \mathrm{~nm}$ line width on the Si substrate after the sol-gel NIL process and final annealing, respectively. As shown in Figure 7, a 50-nm-sized ZnO pattern as well as a sub-micron-sized $\mathrm{ZnO}$ pattern could be directly fabricated from simple NIL, and the defects related to the low modulus of the mold, such as paring of pattern, did not occur during the NIL process due to the use of high modulus h-PDMS mold.

Reverse NIL [92-94] is a patterning technique to transfer patterned two-dimensional layers and to form stacks of micro- and nano-patterned layers on a substrate. Huang et al. [94] developed a reverse NIL process using a hard mold and a PMMA resist. In the reverse NIL process, a polymer resist fills up the trenches of surface protrusions while the polymer resist is spin-coated onto a mold. After curing the polymer film on the mold, the polymer film can be transferred from the mold to the substrate by pressing the mold with the coated polymer film onto the substrate at a temperature around the glass transition temperature $\left(T_{g}\right)$. The replication of the pattern of the mold is simply achieved by spin-coating the resist on the mold in the reverse NIL process. Reverse NIL can also fabricate nano-patterns with functional materials directly by using a soft mold and a functional resist. 
(a)

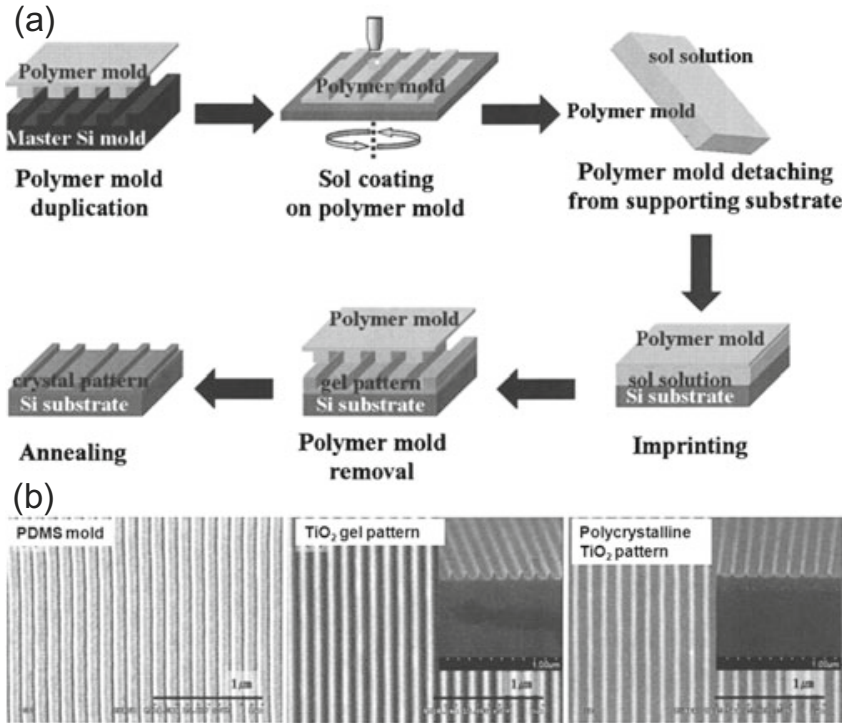

Fig. 8. (a) Schematic diagrams of $\mathrm{TiO}_{2}$ sol-based reverse imprinting process. (b) SEM micrographs of the PDMS mold and the imprinted $\mathrm{TiO}_{2}$ gel patterned layer and polycrystalline $\mathrm{TiO}_{2}$-patterned layer after annealing at $700{ }^{\circ} \mathrm{C}$. Reproduced with permission from reference [100]. Copyright 2009, American Institute of Physics.

Our group developed a reverse NIL process using a h-PDMS and $\mathrm{TiO}_{2}$ sol to fabricate 50-nm-sized nanopatterns [100]. An ethanol-based $\mathrm{TiO}_{2}$ sol was synthesized by mixing tetrabutylorthotitanate precursor and diethanolamine in ethanol. As shown in Figure 8a, the $\mathrm{TiO}_{2}$ sol was spin-coated on the h-PDMS mold and was transferred to the Si wafer substrate by reverse NIL at 5 atm and $200{ }^{\circ} \mathrm{C}$. Finally, the imprinted $\mathrm{TiO}_{2}$ gel pattern on the Si substrate was annealed at $400-700{ }^{\circ} \mathrm{C}$ in air ambient and converted to a pure inorganic $\mathrm{TiO}_{2}$ pattern. Figure $8 \mathrm{~b}$ shows SEM micrographs of the PDMS mold, the imprinted $\mathrm{TiO}_{2}$-gel patterned layer and polycrystalline $\mathrm{TiO}_{2}$ patterned layer after annealing at $700{ }^{\circ} \mathrm{C}$. Similar to the sol-gel NIL process, the dimension of the $\mathrm{TiO}_{2}$ gel pattern and the polycrystalline $\mathrm{TiO}_{2}$ pattern were shrunk compared to the PDMS pattern due to removal of the solvent during the NIL process and close packing during the annealing process.

Although the h-PDMS has higher modulus than the normal PDMS, its modulus is not enough to fabricate sub50-nm-sized pattern with high density and high aspect ratio in the sol-gel NIL process. To overcome this limitation, a harder mold with low surface energy and high permeability should be used in the NIL process. McGehee group developed a reverse NIL process using a $\mathrm{TiO}_{2}$ sol and a hard polymer mold made from anodic alumina (AAO) templates in order to achieve sub-50-nmsized patterns with high aspect ratio [101]. In their work, PMMA with high modulus $(\sim 2-3 \mathrm{GPa})$ was used as a mold material. PMMA solution was spin-coated onto AAO template with pore diameter of 35-65 nm. After the spincoating and baking of the PMMA solution, PDMS as the backing layer for the mold was coated on the PMMA layer

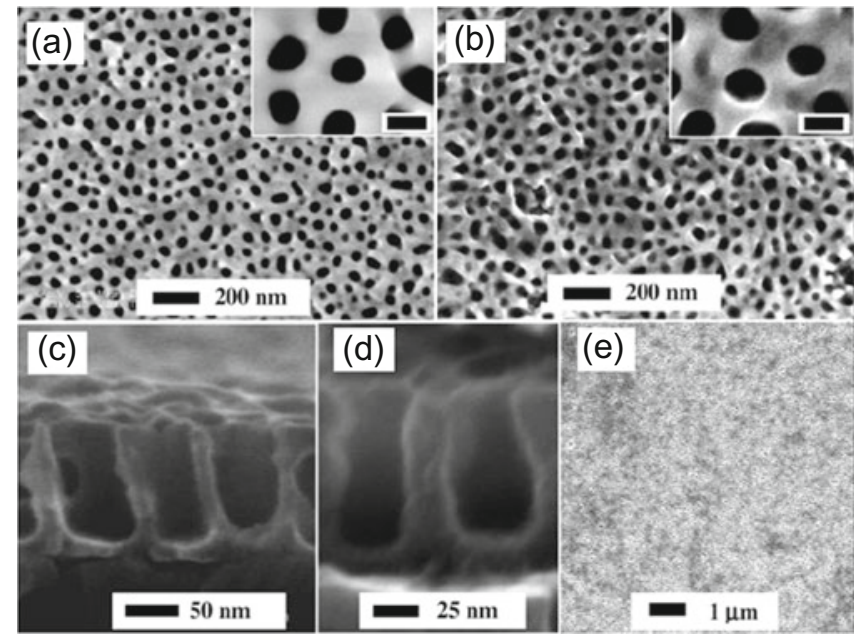

Fig. 9. SEM images of (a) typical initial AAO template, (b) typical embossed $\mathrm{TiO}_{2}$ structures after PMMA removal with acetonitrile, the average pore diameter is $45 \mathrm{~nm}$, (c) embossed $\mathrm{TiO}_{2}$ structures on fluorine-doped tin oxide substrate after calcinations (cross-section), the average pore diameter is larger because the initial template used has larger pore diameter, (d) smaller-diameter pores with one showing $30 \mathrm{~nm}$ diameter and (e) embossed $\mathrm{TiO}_{2}$ at a larger scale showing uniformity of the replication. The insets in (a) and (b) are respectively images at a higher magnification; the scale bar corresponds to $50 \mathrm{~nm}$. Reproduced with permission from reference [101]. Copyright 2005, American Chemical Society.

and cured. Finally, the AAO template was removed by wet etching. They investigated paring of the mold pattern according to mold modulus and interspacing of the mold pattern and demonstrated that high modulus PMMA was more suitable to molding on the AAO template with sub50-nm-sized pores than the h-PDMS, because paring and aggregation of the pattern occurred in the h-PDMS mold and not in the PMMA mold. Next, they performed reverse NIL using the PMMA mold and $\mathrm{TiO}_{2}$ sol mixed with $\mathrm{TiO}_{2}, \mathrm{HCl}$ and 2-propanol, rather than an embossing process, to prevent air trapping between the $\mathrm{TiO}_{2}$ sol and the mold interface. After the reverse NIL process, the $\mathrm{TiO}_{2}$ gel pattern was converted into the crystalline $\mathrm{TiO}_{2}$ pattern by annealing at $600{ }^{\circ} \mathrm{C}$. In Figure 9, SEM micrographs of the AAO template and $\mathrm{TiO}_{2}$ nano-structures are shown.

NIL or reverse NIL using a sol-gel solution containing an organic solvent requires a temperature over the boiling point of the solvent during imprinting for evaporating and removing the solvent. Thus, heating and cooling cycles are essential. Ganesan et al. developed an advanced UV NIL process called step-and-flash imprint lithography (S-FIL) using a sol-gel solution that did not contain an organic solvent [102]. They formulated acrylate-based S-FIL resist consisting of an allyl-functionalized titanium complex mixed with reactive diluents. Similar to the conventional S-FIL process, the $\mathrm{TiO}_{2}$ resist was deposited on an $\mathrm{Si}$ wafer substrate not by spin-coating but drop dispensing. Next, the quartz template with $100 \mathrm{~nm}$ grating was pressed down on the resist at a pressure of 500 mbar 


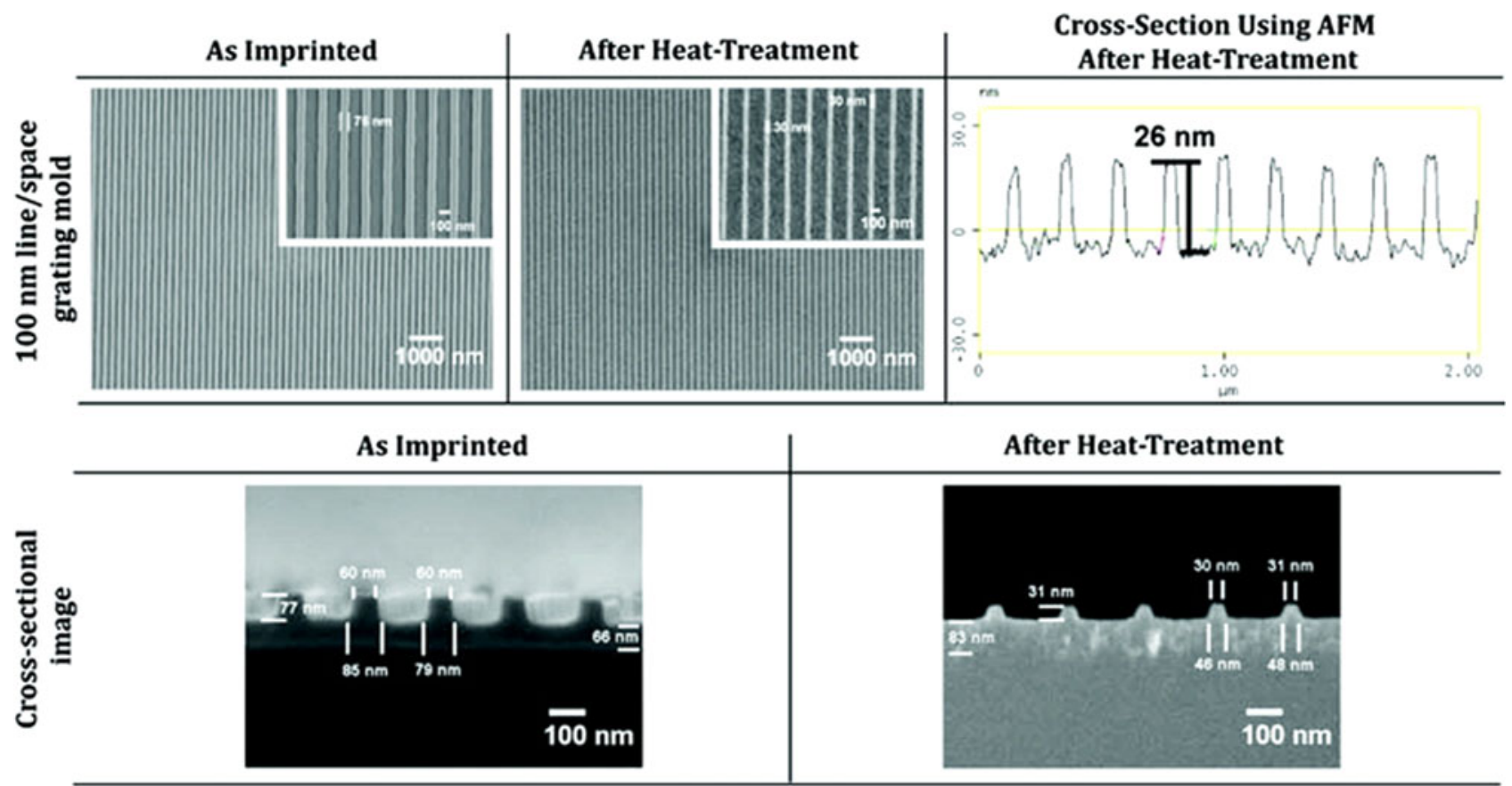

Fig. 10. (Color online) Composite SEM images of as-imprinted and heat-treated structures of $\mathrm{TiO}_{2}$. The insets show the gratings at higher magnification. The AFM line traces of the corresponding heat-treated imprinted structures are shown on the right. Cross-sectional SEM image of the gratings before and after the heat treatment shows the presence of a slight trapezoidal cross-section. Differences in the residual layer thickness within an imprint may arise from slight variations in the degree of flatness of the wafer and/or inaccuracies in template alignment. Reprinted with permission from reference [102]. Copyright 2012, American Chemical Society.

(a)

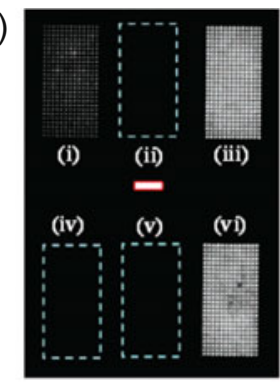

(c)

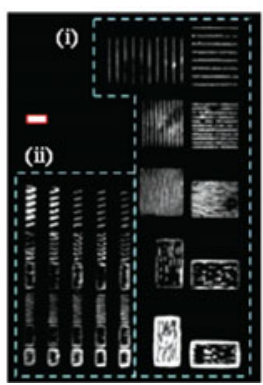

(b)

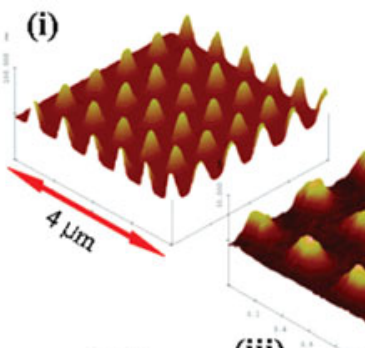

(iii)

(d)

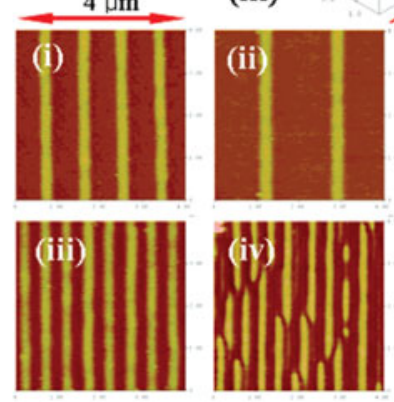

(ii)
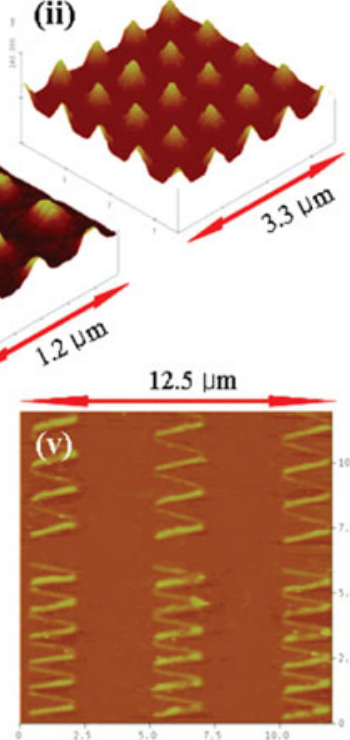

Fig. 11. (Color online) Nano-imprinted gold nanofeatures. Optical dark field images of (a) nanodots and (c) nanowires (inset scale bar corresponds to $5 \mu \mathrm{m})$. AFM topography images of (b) nanodots, (d(i-iv)) straight nanowires and (d(v)) serpentine nanowires. Reproduced with permission from reference [112]. Copyright 2007, American Chemical Society.

for $120 \mathrm{~s}$ to fill the protrusion of the template. Afterwards, broadband UV light was irradiated through the quartz template to photo-polymerize the imprinted resist for $120 \mathrm{~s}$. After the imprinting process, the imprinted $\mathrm{TiO}_{2}$ gel patterns were annealed at $450{ }^{\circ} \mathrm{C}$ for $1 \mathrm{~h}$ in air ambient to remove the organic components and drive the transformation of $\mathrm{TiO}_{2}$ gel to anatase $\mathrm{TiO}_{2}$. During the imprinting process, volume shrinkage of the imprinted pattern inevitably occurred due to the photo-polymerization of the acrylate-based monomer. After the annealing process, the imprinted $\mathrm{TiO}_{2}$ gel patterns were shrunk again due to the removal of the organics and close packing 
induced by crystallization. Figure 10 shows the imprinted $\mathrm{TiO}_{2}$ gel patterns and $\mathrm{TiO}_{2}$ patterns as small as $30 \mathrm{~nm}$ width after the annealing.

\subsection{NIL processes using nanoparticle-based solutions}

Currently, metal, dielectric and semiconductor-based nanoparticles have been used in various fields such as biomedical applications, gas sensors, solar cells, field effect transistors, printed electronics and light-emitting devices. Nanomaterials including nanoparticles show significant distinguishing properties from their large surface area to volume ratio, spatial confinement and large surface energy compared to bulk materials. Especially, organic solvent-based nanoparticle solutions have been utilized for useful processing in diverse applications. Various direct patterning processes such as micro-contact printing $(\mu \mathrm{CP})[103-105]$, ink-jet printing [106-108] and screen printing [109-111] have been developed to fabricate nano- and micro-structures using nanoparticle solutions. However, these processes have limitations of resolution, throughput and cost efficiency for mass production of functional nano-structures. In recent years, NIL processes based on nanoparticle solutions containing metal, metal oxide and semiconductor materials have been developed to fabricate functional nano-structures directly. Low viscosity of nanoparticle solutions enables nanoparticles to fill the cavity of the imprint mold at low pressure and low melting temperature of nanoparticles according to their spatial effect. Similar to sol-gel NIL, nanoparticle solutions can be formed into the patterned solid-state layer through the NIL process, and the imprinted nanoparticle layer can be converted into a continuous patterned layer through annealing, which promotes solid bridging and close packing.

Ko et al. [112] developed an NIL process using a gold nanoparticle solution. In their work, $\alpha$-terpineol-based gold nanoparticle solution containing 2-3-nm-sized gold nanoparticles was used in the thermal NIL process using a PDMS mold on an $\mathrm{SiO}_{2} / \mathrm{Si}$ wafer substrate at $80{ }^{\circ} \mathrm{C}$ and 5 psi. During the NIL process, the nanoparticle solution filled the protrusion of the mold, and the solvent was evaporated and removed through the PDMS mold. After the NIL process, the imprinted sample was heated on a hot plate at $140{ }^{\circ} \mathrm{C}$ to achieve a continuous gold film from the imprinted gold nanoparticle film. Compared to the melting temperature of bulk gold $\left(1063{ }^{\circ} \mathrm{C}\right)$, 2-3-nm-sized gold nanoparticles used in their work had very low melting temperature $\left(130-140{ }^{\circ} \mathrm{C}\right)$. Thus, continuous and patterned gold film could be fabricated by annealing at $140{ }^{\circ} \mathrm{C}$. In Figure 11, optical dark field images and atomic force microscope (AFM) topography images of imprinted gold nanodots and nanowires are shown. Due to low viscosity and surface wetting of the gold nanoparticle solution, nano-patterns could be formed on the substrate with negligible residual layer.

Our group developed a direct NIL process using an ITO nanoparticle solution for optoelectronic applications [113]. In this work, isopropyl alcohol (IPA)-based (a)

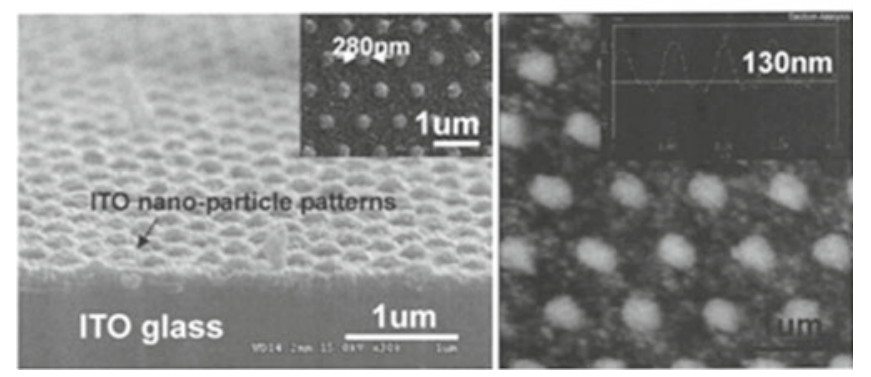

Fig. 12. (a) SEM and (b) AFM images of the ITO nanopatterns on the ITO-coated glass after final annealing. Reproduced with permission from reference [113]. Copyright 2009, American Institute of Physics.

solution containing 20 wt.\% ITO nanoparticles with a diameter of $50 \mathrm{~nm}$ was purchased from Advanced NanoProducts and diluted by adding DMF to a 10 wt.\% ITO nanoparticle solution to achieve a high-resolution ITO nano-pattern and prevent easy evaporation of IPA during spin-coating. The diluted ITO nanoparticle solution was spin-coated onto ITO-coated glass, and thermal NIL was done using a PDMS mold at $5 \times 10^{5} \mathrm{~Pa}$ and $100{ }^{\circ} \mathrm{C}$ for $1 \mathrm{~h}$. During the NIL process, the ITO nanoparticle solution filled the cavity of the PDMS mold and heating at $100{ }^{\circ} \mathrm{C}$ promoted the removal of organic solvents in the ITO nanoparticle solution by absorption into the PDMS mold. After the NIL process, the imprinted sample was annealed at $500{ }^{\circ} \mathrm{C}$ for $2 \mathrm{~h}$ at air ambient in order to homogenize the ITO nanoparticle pattern and increase the conductivity of the patterned ITO layer. To achieve a high fidelity nano-pattern by NIL, sufficient fluidity of the imprint resist should be guaranteed for complete filling of the cavity of the mold. In this work, the DMF solvent decreased the viscosity of the ITO nanoparticle solution and maintained the residual solvent after the spin-coating. Thus, an ITO nano-pattern could be uniformly formed. Figures $12 \mathrm{a}$ and $12 \mathrm{~b}$ exhibit SEM and AFM images of the ITO nano-patterns on the ITO-coated glass after final annealing. The patterned ITO-coated glass with ITO nanoparticles showed higher transmittance in the visible wavelength regions than the pre-annealed ITO glass due to reduction of reflections on the ITO surface by the ITO nanoparticle pattern. Also, the sheet resistance of the ITO nanoparticle patterns on the ITO-coated glass was measured to $305.2 \Omega / \square$, which is similar to that of the sputtered ITO glass.

Hampton et al. [114] fabricated cadmium selenide (CdSe) array using NIL (named print technique by them) with a soft mold and CdSe quantum dot (QD) solution in order to build photovoltaic devices. The solution of CdSe QDs in 4-picoline was used as an imprint resist. To satisfy the need for a mold with chemical inertness to QD solution, high gas permeability and low surface energy, perfluoropolyether (PFPE) elastomeric mold was used instead of a PDMS mold in the NIL process. To fabricate the QD array, the CdSe QD solution was coated on ITO-coated glass, and the PFPE mold was placed on the CdSe QD solution film. Then thermal NIL was performed at $85{ }^{\circ} \mathrm{C}$ 

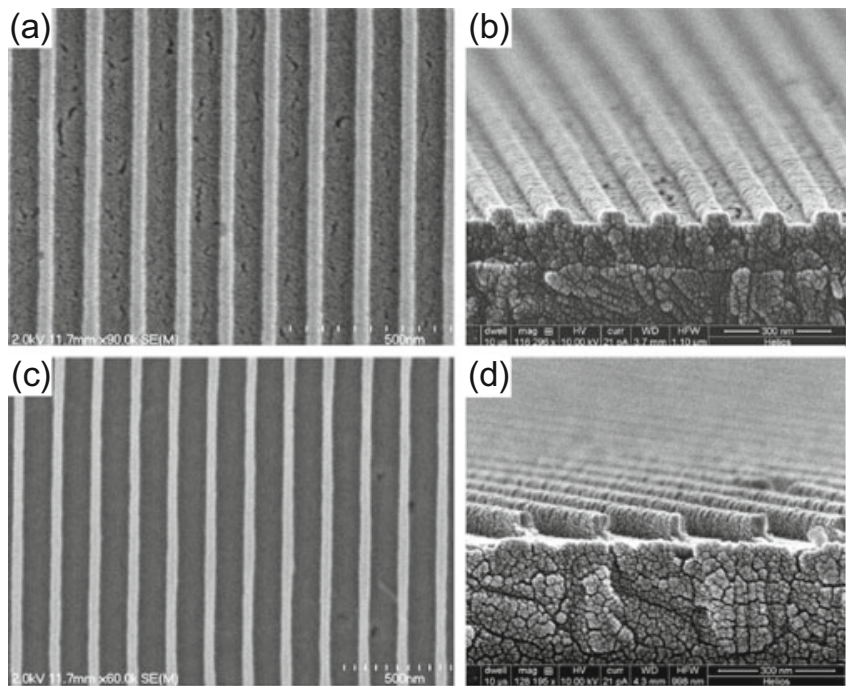

Fig. 13. SEM images of patterned CdSe QDs from a diffraction grating with (a) and (b) a $150 \mathrm{~nm}$ pitch and $45 \mathrm{~nm}$ height and (c) and (d) a $180 \mathrm{~nm}$ pitch and $90 \mathrm{~nm}$ height. Reproduced with permission from reference [114]. Copyright 2010, American Chemical Society.

for 10 min. During the NIL process, gas product and extra organic solvent were removed through the PFPE mold, and the remaining solution with high QD concentration filled the cavity of the mold by capillary action. As a result, nano-patterns could be formed on the substrate as shown in Figure 13. However, a thick residual layer remained after the NIL process, thus, control of initial QD concentration in the solution and pressure for applying extra solution is needed to reduce the thickness of the residual layer.

Most direct NIL processes using a sol-gel solution and a nanoparticle solution require thermal cycling to evaporate and remove a solvent in a solution during the imprinting step. This is critical to fabricate uniform and defect-free nano-structures and inevitably needed to induce sol-gel reaction and cross-link nanoparticles. To evaporate the solvent during the NIL process, a highly permeable polymer mold such as PDMS and PFPE molds must be used. Although solvent evaporation can be solved by using a PDMS mold, large pattern shrinkage inevitably occurs during the NIL process by the volume reduction from solvent evaporation. And, the resolution is limited to $100 \mathrm{~nm}$ due to use of low modulus polymer mold [115]. To overcome these limitations, some studies have been recently established to fabricate functional nano-structures by NIL using nanoparticle-dispersed resin [116-120]. In these studies, a monomer-based resin containing nanoparticles was used as an imprint resist. During the NIL process, the monomer is cross-linked by a photo- or a thermal initiator and converted into the patterned polymer layer. After the NIL process, nanoparticle networks exist in the polymer matrix. Since an organic solvent is not contained in the resist, a rigid mold, such as Si, quartz and nickel molds, which give high resolution $(<10 \mathrm{~nm})$, can be used in the direct NIL process instead of a soft polymer mold.
Lim et al. [116] developed direct $\mathrm{TiO}_{2}$ NIL process using a titanium methacrylate-based resin. They formulated thermally curable imprint resin mixed with a titanium methacrylate monomer, a cross-linker and thermal initiator. Since the imprint resin did not contain an organic solvent, a conventional Si mold could be used in the NIL process. In their work, titanium methacrylate can be dissolved in the low viscosity monomer having high fluidity, and thus, the NIL process can be done at low pressure $(<10$ bar). Prior to the NIL process, the resin was deposited on an Si substrate by spin-coating. Afterwards, the resin layer was firstly imprinted with the Si mold at room temperature and 10 bar to completely fill the cavity of the Si mold with the resin. Secondly, the stack of the mold/resin/Si substrate was heated to $110{ }^{\circ} \mathrm{C}$ for $180 \mathrm{~s}$, while maintaining the pressure, in order to generate the polymerization of the resin. By using the monomer-based $\mathrm{TiO}_{2}$ resin, this process could be performed in the mechanism of a conventional thermoset NIL process using thermally curable monomer-based resin. After the imprinting, the dimension of the imprinted pattern was slightly decreased compared with that of the Si master mold due to polymerization-induced shrinkage. Similar to sol-gel NIL, the imprinted pattern could be converted into pure inorganic pattern by annealing over $400{ }^{\circ} \mathrm{C}$. Figure 14 shows SEM micrographs and AFM images of the imprinted pattern and $\mathrm{TiO}_{2}$ pattern after annealing.

As a similar approach, NIL using a metal nanoparticle-dispersed UV-curable resin was developed by Choi et al. [118]. In their work, Ag colloids were mixed with UV-curable resin with hydroxyl methacrylate and a photo-initiator. Because $\mathrm{Ag}$ nano-powders were not directly dispersed into the $\mathrm{UV}$-curable resin, but $\mathrm{Ag}$ dispersion solution was mixed in the UV-curable resin, dispersant solvents were contained in the Ag-dispersed UV resin. To minimize the amount of solvent in the $\mathrm{Ag}$ dispersed resin, high concentration Ag colloids (70 wt.\%) were applied to the UV-curable resin. Thus, most of the solvents could be evaporated with vacuum assistance, prior to the NIL process. After resin dispensing on a glass substrate, UV NIL was performed using an Si mold containing various electrode line patterns under a pressure of 20 bar. After the imprinting, the imprinted Ag-dispersed resin was thermally annealed for sintering of $\mathrm{Ag}$ nanoparticles and complete curing of the resin. To remove the residue of the imprinted electrode pattern, wet etching followed. Figures 15a-15c show SEM micrographs of the imprinted, sintered and wet-etched electrode pattern, respectively. They investigated the shrinkage rate of the imprinted pattern with Ag concentration and confirmed that the resistivity of the imprinted $\mathrm{Ag}$ resin pattern was in the range of $40-80 \mathrm{n} \Omega \mathrm{m}$. This is a meaningful result indicating that conductive patterns can be fabricated with a simple process and low cost.

Wang et al. [119] developed an NIL process using a conductive UV-curable resin mixed with Ag nanoparticles growing on modified multi-walled carbon nanotubes (MMWNTs). Carbon nanotube (CNT) has been well known to have high mechanical strength and high 


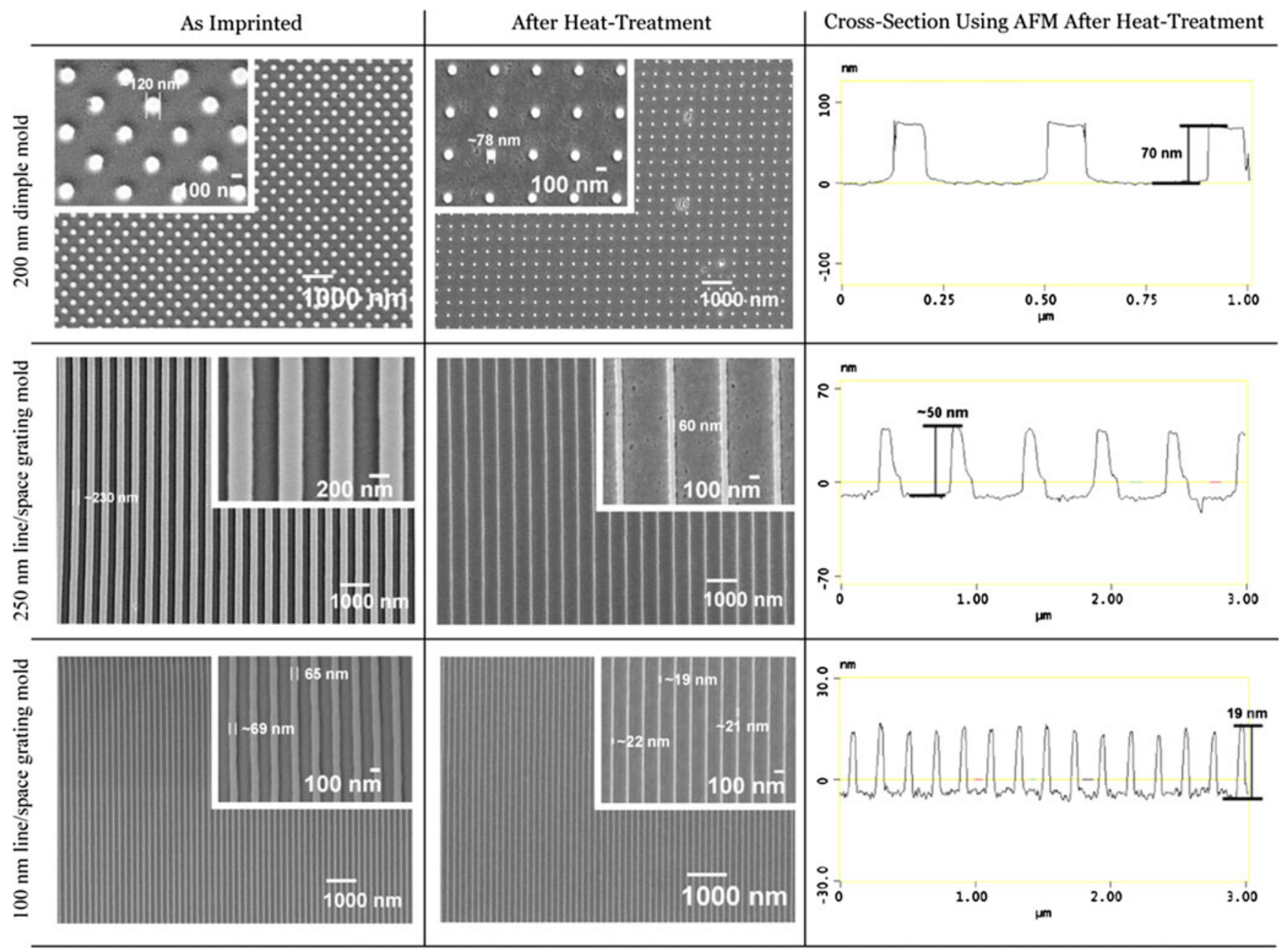

Fig. 14. (Color online) Composite SEM images of various as-imprinted and heat-treated structures using different molds. The insets show the structures at higher magnification. The AFM line trace of the corresponding heat-treated imprinted structures is shown in the right. Reprinted with permission from reference [116]. Copyright 2010, Institute of Physics.

conductivity. MWNT, layers of CNT wrapped together, has larger electrical conductivity than CNT. However, due to difficulty of processing, application of CNT has been limited so far. Wang and coworkers established useful NIL processing to fabricate MWNT-based conductive patterns. Firstly, they formulated the $\mathrm{Ag} / \mathrm{MMWNT}$ composite by mixing MWNT treated with an $\mathrm{H}_{2} \mathrm{SO}_{4} / \mathrm{HNO}_{3}$ mixture with $\mathrm{AgNO}_{3}$ in ethylene glycol solution in an ultrasonic bath. $\mathrm{Ag}$ nanoparticles were synthesized in an MWNT structure to achieve higher conductivity. Secondly, the $\mathrm{Ag} / \mathrm{MMWNT}$ composite was dispersed homogeneously in an acrylic resin containing a photo-initiator. They confirmed that the average size of $\mathrm{Ag}$ nanoparticles grown on the MWNT was $30 \mathrm{~nm}$ and $\mathrm{Ag} / \mathrm{MMWNT}$ in acrylic resin was homogeneously mixed. The minimal of 5 wt.\% $\mathrm{Ag} / \mathrm{MMWNT}$ resin was $42 \Omega \mathrm{cm}$, and $\mathrm{Ag} /$ MMWNT resin showed resistivity two orders of magnitude lower than that of MMWNT resin. They explained this high conductivity of $\mathrm{Ag} / \mathrm{MMWNT}$ resin by the incorporation of $\mathrm{Ag}$ nanoparticles, which reduced the contact resistance and tunneling resistance between the two MWNTs. By UV NIL using a PDMS mold, various micro- scaled $\mathrm{Ag} / \mathrm{MMWNT}$ resin patterns were formed on a polyethylene terephthalate substrate as shown in Figure 16. In comparison to other direct NIL processes, a conductive pattern could be fabricated by only one step of NIL without post annealing.

\subsection{NIL processes using SOG resists}

Spin-on-glass has been investigated as an imprint resist due to its higher plasma-etch resistance compared to a conventional imprint resin and the usefulness of converting to $\mathrm{SiO}_{2}$ by thermal annealing. Many researchers have demonstrated NIL using a SOG resist [121-127]. Matsui and his coworkers have investigated RT-NIL using SOG resist intensively to avoid change of pattern accuracy with thermal cycling in conventional NIL [121-124]. In their early research, a SOG resist which contains organosilica $\left(\mathrm{Si}(\mathrm{OH})_{4}+\mathrm{R} 1 \mathrm{COOR} 2\right)$ solution in alcohol was used as an imprint resist [121]. The SOG resist was spin-coated on an Si substrate and an Si mold was immediately pressed on the SOG-coated $\mathrm{Si}$ substrate without baking to 

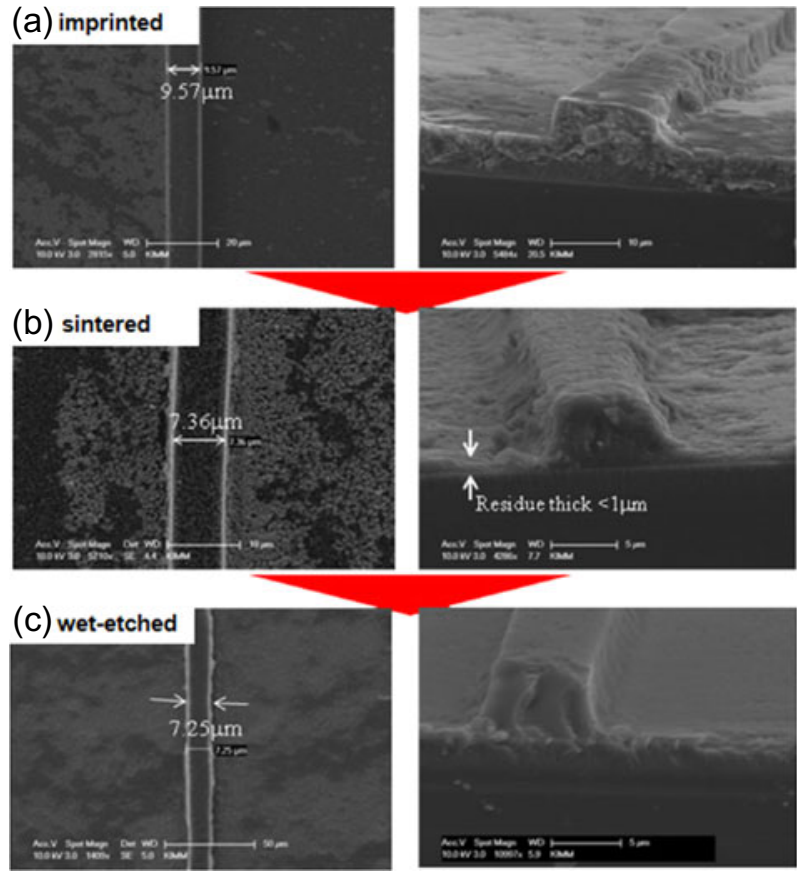

Fig. 15. (Color online) Pattern shrinkage accumulated at each process step: (a) after imprint, (b) after sintering and (c) after wet-chemical etch. Reproduced with permission from reference [118]. Copyright 2009, The Japan Society of Applied Physics.

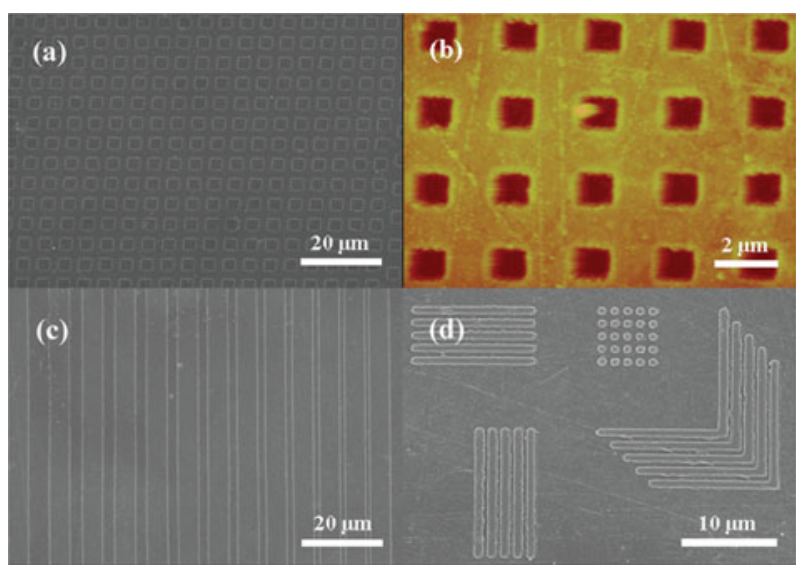

Fig. 16. (Color online) Images of $\mathrm{Ag} / \mathrm{MMWNT}$-resin nanocomposite NIL patterns. (a) SEM image and (b) AFM image of the square grating pattern with $\mathrm{Ag} / \mathrm{MMWNT}$ nanofillers at loading rate of 5 wt.\%, (c) SEM images of rectangle grating pattern with line-width transits from 4 to $1 \mu \mathrm{m}$ and (d) multiplex patterns with Ag/MMWNT nanofillers at loading rate of 5 wt.\%. Reprinted with permission from reference [119]. Copyright 2009, American Chemical Society.

prevent drying of the SOG layer at 2.5 MPa for $10 \mathrm{~min}$. As a result, SOG patterns with $200 \mathrm{~nm}$ line widths were fabricated on the Si substrate at room temperature. Although the SOG resist could be used in RT-NIL, it had a technical limitation in that SOG hardens gradually due to reaction with water in the ambient air. And organic solvent in the SOG is an obstacle to uniform patterning on
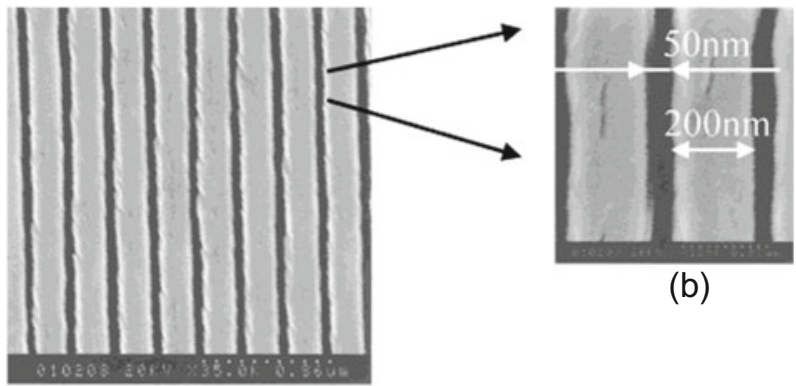

(b)

(a)

Fig. 17. SEM micrographs of patterns with $50 \mathrm{~nm}$ linewidth and $200 \mathrm{~nm}$ pitch replicated in HSQ using RT-NIL. Reprinted with permission from reference [122]. Copyright 2002, The Japan Society of Applied Physics.

large areas because of the evaporation of the solvent during the imprinting. To overcome this technical limitation, Matsui group developed NIL using hydrogen silsequioxane (HSQ), one kind of SOG [122]. In their work, HSQ solution was spin-coated on an Si substrate and prebaked to evaporate organic solvent and to have moderate fluidity for physical deformation with a mold. Next, imprinting with an Si mold was performed on the HSQ-coated Si substrate at room temperature. Prebaked HSQ layer has higher viscosity than a conventional monomer-based resin. Thus, high pressure was applied during the imprinting process. Through this RT-NIL process, 50-nm-scaled patterns were fabricated as shown in Figure 17. In this process, the modulus and the viscosity of the prebaked HSQ layer are important to achieve a high fidelity pattern. The HSQ layer prebaked at $50-150{ }^{\circ} \mathrm{C}$ could be imprinted at a pressure of above $1 \mathrm{MPa}$, but the HSQ layer prebaked at $200{ }^{\circ} \mathrm{C}$ was difficult to be imprinted due to its high hardness.

In the case of using spin-coated HSQ layer, a high pressure is required to define a pattern during an imprinting, and a residual layer inevitably remains due to high viscosity of the HSQ. To solve these problems, Matsui group proposed the NIL process using a liquid phase HSQ and a PDMS mold [123]. Since the PDMS can absorb an organic solvent easily and has high gas permeability, the solvent can be absorbed into the PDMS mold during the imprinting and removed by evaporating by diffusion through the PDMS mold. In the process which Matsui group developed, the HSQ was dispensed on a substrate by direct dropping and was immediately imprinted with the PDMS mold at room temperature. According to the modulus of the PDMS mold, including normal PDMS and h-PDMS, and the amount of dispensed HSQ, residual layers of micro-scaled line patterns could be minimized at moderate imprint pressure of $0.2-10 \mathrm{MPa}$.

Our group has further upgraded the NIL process using a liquid phase HSQ and a PDMS mold in order to minimize pattern shrinkage caused by solvent evaporation, and achieve high fidelity pattern transferring [127]. In the NIL process using an organic solvent-based resist and a PDMS mold, severe pattern shrinkage inevitably 
(a)

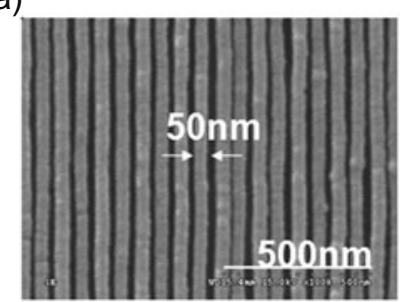

(c)

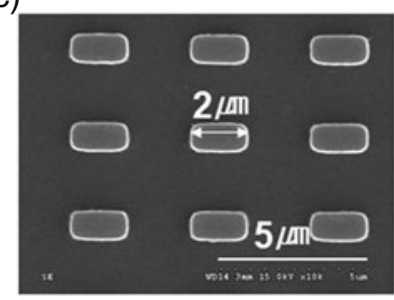

(d)
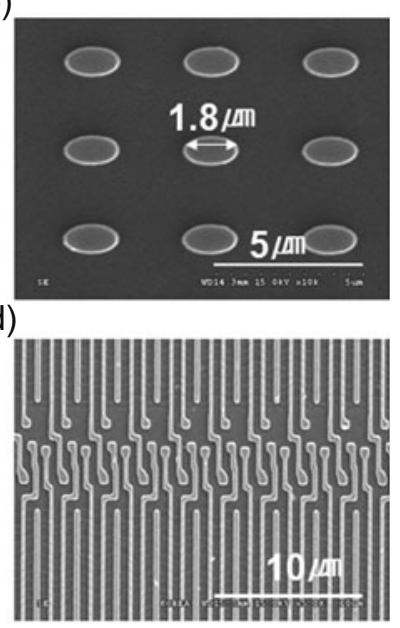

(e)

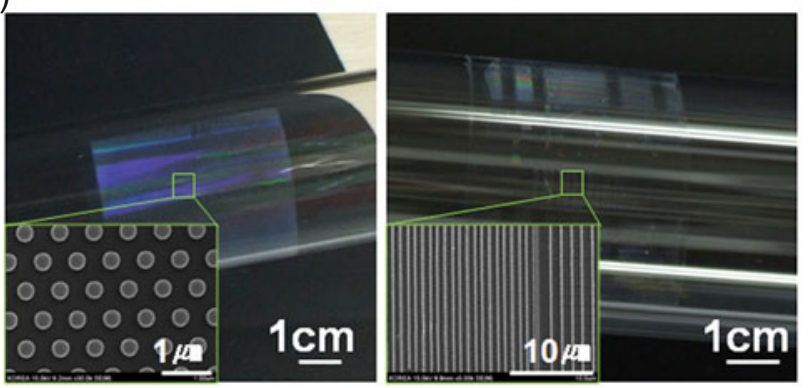

Fig. 18. (Color online) SEM micrographs of the HSQ nanopatterns with different shapes. (a) The 50-nm-sized HSQ patterns. (b), (c) The micro-sized HSQ patterns. (d) The HSQ patterns with dense, meandering line shape. (e) Photographs and SEM micrographs of the HSQ nano-structures on the curved substrate. Reproduced with permission from reference [127]. Copyright 2011, American Institute of Physics.

occurs during imprinting due to the large volume reduction with solvent evaporation into the PDMS when the resist is directly imprinted with the PDMS mold without prebaking. To avoid severe pattern shrinkage, an HSQ resist was spin-coated on a patterned PDMS mold and then was transferred onto a substrate by imprinting. When the HSQ resist was spin-coated on the PDMS mold, most of the organic solvent in the HSQ was evaporated due to its high volatility, and some of the organic solvent was absorbed into the PDMS mold. By spin-coating the HSQ resist on the PDMS mold, the protrusion pattern of the PDMS mold could be simply replicated with the HSQ layer including little organic solvent. After the spincoating, the HSQ layer on the PDMS mold was transferred on the Si substrate by imprinting at $0.5 \mathrm{MPa}$ and room temperature for $30 \mathrm{~s}$ under vacuum. Figures $18 \mathrm{a}-$ 18d show the SEM micrographs of various HSQ patterns, including $50 \mathrm{~nm}$ line-width pattern, micro-sized dot pattern and sub-micron line-width pattern, formed by the NIL process. In this process, the remaining organic solvent in the HSQ layer is critical for transferring the patterned HSQ layer on a substrate. The mechanism of the HSQ transferring can be explained by "solid bridging" at the interface between the HSQ layer and the substrate. When the HSQ-coated PDMS mold is in contact with the substrate, the dissolved HSQ is extracted and acts as a glue layer to adhere with the substrate while the remaining solvent evaporates. On the other hand, the absorbed solvent in the PDMS mold is discharged into the interface between the PDMS and the HSQ layer during the imprinting. Thus, solid bridging phenomenon does not occur due to increase in the amount of the solvent at the interface between the PDMS and the HSQ layer. Moreover, since PDMS has lower surface energy than the Si substrate, the adhesive force at the HSQ/substrate is stronger than the adhesive force at the HSQ/PDMS. Thus, the HSQ layer on the PDMS mold can be easily transferred to the substrate. Through this NIL process, HSQ pattern could be also transferred on the curved quartz substrate as shown in Figure 18e.

\section{Applications}

NIL technology has been applied to diverse electronic, magnetic, bio- and optical devices which require nano- and micro-sized structures due to its high resolution and high throughput, large area capability and non-limitation of substrate. Moreover, a flexible substrate and a curved substrate can be patterned by NIL process [128-133]. These application fields include organic and inorganic thin film transistors (TFTs) [134-139], optical elements and film for various displays [140-142], light-emitting devices including LEDs and OLEDs [143-152], patterned magnetic media $[153,154]$, next-generation random access memory (RAM) devices including resistive RAM and phasechange RAM [155-163], and organic and thin film solar cells [164-168]. Various types of nano- and microstructures including one-, two- and three-dimensional structures have been fabricated by NIL and have been applied to diverse devices to enhance the overall performance. In this section, we would like to discuss briefly several applications, including LED, OLED and solar cells, related to NIL-based direct patterning.

\subsection{Applications for light-emitting devices}

Direct NIL using a functional resist can be applied to lightemitting devices for enhancing the light extraction since it can directly fabricate inorganic or organic-inorganic hybrid nano- and micro-structures with desirable optical properties such as high refractive index and high transmittance. In LED and OLED devices, the light generated from active layer is mostly trapped inside the device by total internal reflection at the interface between the device and air. Total internal reflection is caused by a large difference in refractive index between the device materials and air. In the case of GaN-based LED, the critical angle for the photon to escape from the GaN to air is about $24^{\circ}$ at its emitting region. Except for the escape cone region, most of the photons are internally reflected and converted to heat inside the device. Simply, 

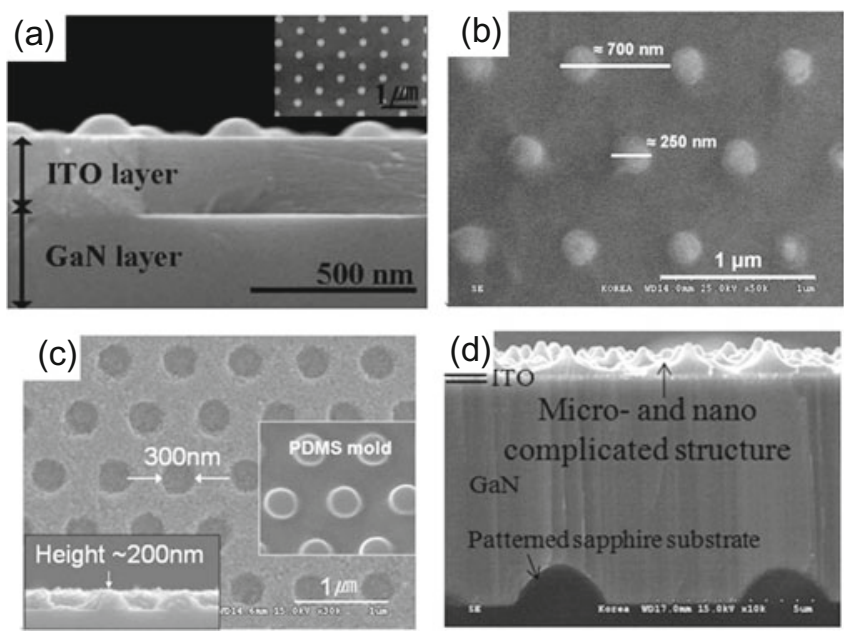

Fig. 19. Various patterns on LED structures, fabricated by NIL-based direct patterning processes: (a) polycrystalline sol-gel $\mathrm{TiO}_{2}$ pattern. Reproduced with permission from reference [180]. Copyright 2010, Elsevier. (b) Polycrystalline sol-gel $\mathrm{ZnO}$ pattern. Reproduced with permission from reference [181]. Copyright 2011, Elsevier. (c) ITO nanoparticle pattern. Reproduced by permission of The Electrochemical Society [182]. (d) $\mathrm{TiO}_{2}$-rich polymeric pattern on the ITO electrode. Reproduced from Cho et al. [183], licensee Springer.

the textured top surface, intermediate layer and bottom substrate of the LED or OLED suppress the total internal reflection by scattering the light emitted from the active layer outward. To fabricate textured structures, various patterning processes, such as nanosphere lithography $[169,170]$, nanorod growth [171-173], e-beam lithography $[174,175]$, laser interference lithography $[176,177]$ and wet etching $[178,179]$, have been investigated. In nanosphere lithography, photolithography, e-beam lithography and laser interference lithography, resist pattern is firstly formed on the device and then plasma etching is followed to fabricate the textured surface including roughened surface and photonic crystals on the light-emitting devices. However, plasma etching induces the degradation of electrical properties of the devices. And the patterning procedure of these techniques is complex and requires high cost. In nanorod growth and wet-etching methods, the fabrication of the optimized textured structure for light-emitting devices is difficult due to the limitation of controlling pattern dimension. Therefore, direct NIL processes using a functional resist, which can fabricate directly functional nano-patterns without plasma etching, have been recently investigated to enhance the light extraction of lightemitting devices without the degradation of electrical properties. We will discuss direct NIL process for LEDs and OLEDs mainly by introducing our own results.

Our group has tried to introduce nano-structures into LEDs using the NIL process with various functional resists. As a first attempt, pure inorganic $\mathrm{TiO}_{2}$ sub-micron patterns were formed on the ITO electrode of GaN-based blue LED wafer by $\mathrm{TiO}_{2}$ sol-gel NIL using a PDMS mold followed by annealing at $600{ }^{\circ} \mathrm{C}$ as shown in Figure 19a [180]. We investigated the effect on photolu- minescence (PL) intensity with the existence of the residual layer of the $\mathrm{TiO}_{2}$ pattern. When the $\mathrm{TiO}_{2}$ pattern was formed on the ITO surface without $\mathrm{TiO}_{2}$ residual layer, large increase of PL intensity was observed. This result can be explained by the effective refractive index of the ITO layer being modulated locally by the $\mathrm{TiO}_{2}$ patterns, and total internal reflection was suppressed by the light scattering at the $\mathrm{TiO}_{2}$ pattern on the ITO electrode. When a 50-nm-thick residual layer of the $\mathrm{TiO}_{2}$ pattern existed on the ITO surface, the PL intensity of the $\mathrm{TiO}_{2}$ patterned LED was weaker than the LED without $\mathrm{TiO}_{2}$ pattern due to low transmittance of $\mathrm{TiO}_{2}$ and absorption of the $\mathrm{He}-\mathrm{Cd}$ laser and the light emitted from the active layer. In similar work, we applied ZnO sol-gel NIL to LED devices [181]. In Figure 19b, an SEM micrograph of the inorganic $\mathrm{ZnO}$ sub-micron pattern is shown. This $\mathrm{ZnO}$ pattern was fabricated on the ITO electrode of the GaNbased LED by imprinting of $\mathrm{ZnO}$ sol with a PDMS mold and annealing at $500{ }^{\circ} \mathrm{C}$ in air ambient. LED devices with patterned sapphire substrate (PSS) and without PSS were used in this work. The PSS has micro-sized patterns for the growth of GaN epitaxial layer with decreased dislocation density, and it helps to increase light extraction by light scattering at the micro-sized pattern. By the $\mathrm{ZnO}$ pattern, the electroluminescence (EL) intensities of PSSLED and nonPSS-LED were increased up to $19 \%$ and $20 \%$ compared to that of the LED without the $\mathrm{ZnO}$ pattern at $20 \mathrm{~mA}$, respectively. When the GaN LED was grown on the PSS, light extraction efficiency has already increased by the surface pattern of PSS. Then, EL intensity was further increased by $19 \%$. The electrical performance of the LED device with the $\mathrm{ZnO}$ pattern was not degraded compared to the LED device without the $\mathrm{ZnO}$ pattern in $I-V$ characteristics, since $\mathrm{ZnO}$ sol-gel NIL could directly fabricate the $\mathrm{ZnO}$ pattern without plasma etching, which induces electrical degradation with plasma damage in GaN and ITO layers. We also applied the nano-printing process using ITO nanoparticle solution and a PDMS mold to the LED structure [182]. The ITO solution with $50 \mathrm{~nm}$ average diameter ITO nanoparticles in IPA was spin-coated on the PDMS mold, which has a nanopillar array with a diameter of $300 \mathrm{~nm}$, a pitch of $700 \mathrm{~nm}$ and a height of $220 \mathrm{~nm}$. The thickness of the ITO layer could be controlled by adjusting spin speed, and spin-coating was performed at $5000 \mathrm{rpm}$ for $30 \mathrm{~s}$ in order to minimize the residual layer of the ITO pattern. Then the ITO-coated PDMS mold was pressed on the ITO surface of the GaN-based LED at 5 bar and $100{ }^{\circ} \mathrm{C}$ for $10 \mathrm{~min}$. After detaching the PDMS mold from the LED substrate, the sample was annealed at $500{ }^{\circ} \mathrm{C}$ for $2 \mathrm{~h}$ in vacuum ambient in order to enhance the conductivity of the ITO nanoparticle layer. As shown in Figure 19c, the ITO nanoparticle pattern with nanohole array was formed on the ITO electrode of the GaN-based LED and was used as a current spreading layer. Similar to the result of $\mathrm{ZnO}$ sol-gel patterning on the $\mathrm{LED}$, the EL intensity of the LED with the ITO pattern was increased by $28 \%$ compared to that of the LED without the ITO pattern at $20 \mathrm{~mA}$ by light scattering at the ITO surface pattern and decrease of total internal reflection. The electrical property of the LED device with ITO nanoparticle 
pattern was similarly maintained with that of the LED devices without the ITO nanoparticle pattern. Figure 19d is an SEM micrograph of the $\mathrm{TiO}_{2}$-rich polymer pattern on the GaN-based LED structure, fabricated by thermal NIL using a PDMS mold and a $\mathrm{TiO}_{2}$ nanoparticle-dispersed resin [183]. In this work, randomly distributed nano- and micro- (RDNM) patterns were formed on a sapphire substrate by photoelectrochemical etching, and the PDMS mold was replicated from the RDNM pattern on the sapphire substrate by PDMS molding. The resin was spincoated on the LED device and thermal NIL was done. The RDNM pattern was fabricated on the ITO electrode layer of GaN-based LED. Since the $\mathrm{TiO}_{2}$ resin had a high refractive index (2.08) and high transmittance $(>90 \%)$ in the blue LED emission wavelength region, the RDNM pattern could modulate and extract the light emitted from the active layer directly. By simple one-step imprinting, a highly refractive pattern which is helpful to enhance the light extraction efficiency of the LED could be formed on the LED device. Through this NIL process, the LED device with the RDNM pattern exhibited $13 \%$ stronger EL intensity than that of the LED device without the RDNM pattern, while the electrical properties of the LED device with RDNM were not degraded.

Our group fabricated a silica-based moth-eye pattern with high mechanical strength on a green OLED device using a nano-printing process with a PDMS mold and a HSQ solution [184]. The HSQ solution was spin-coated on the PDMS mold with the moth-eye pattern, then the HSQ layer was transferred on the glass substrate by nanoprinting at 5 bar and room temperature for $1 \mathrm{~min}$. After that, the HSQ-based moth-eye pattern was converted into a silica-based moth-eye pattern by UV ozone treatment and annealing at $450{ }^{\circ} \mathrm{C}$ for $1 \mathrm{~h}$ as shown in the AFM image of Figure 20a. The moth-eye pattern is well known to reduce the total internal reflection of the light by its gradual change of the average refractive index of the media. When the silica-based moth-eye pattern was formed on the glass substrate by the nano-printing with the HSQ solution, the transmittance of the glass substrate was increased up to $3-4 \%$ at wavelengths above $350 \mathrm{~nm}$. Thus, the silica-based moth-eye pattern was formed on the encapsulation glass of the OLED device. The EL measurement result of Figure 20b shows that the presence of the moth-eye patterns on the OLED devices resulted in the enhancement of EL intensity by up to $9.29 \%$ at $525 \mathrm{~nm}$. The light emitted from the active layer of the OLED device proceeds toward random directions. Thus, the light at the interface between the device and air has various incident angles. According to Snell's law, the critical angle of total internal reflection is around $48^{\circ}$ at the top encapsulation glass/air interface. The photons with a higher incident angle than the critical angle are mostly reflected inside the device. Thus, the light extraction efficiency of the OLED is very low, similar to that of the LED. In our work, the total internal reflection at the encapsulation glass/air interface was suppressed by the presence of the silica-based moth-eye pattern on the capsulation glass. Thus, light output of the OLED with the moth-eye pattern could be increased.

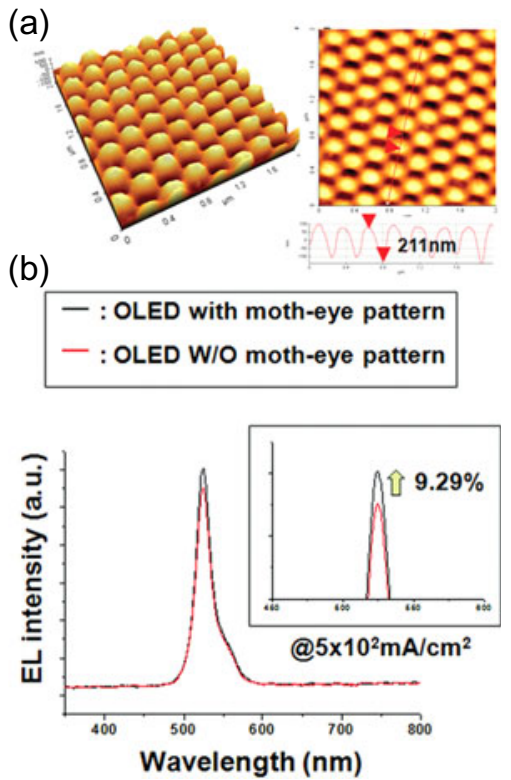

Fig. 20. (Color online) (a) AFM micrographs of the silica moth-eye patterns on the glass substrate. (b) EL spectra of OLED devices with and without the silica moth-eye patterns at a dc current density of $5.0 \times 10^{2} \mathrm{~mA} / \mathrm{cm}^{2}$. Reproduced by permission of The Electrochemical Society [184].

\subsection{Applications for solar cells}

Recently, many studies for achieving high efficiency of solar cells have been intensively studied with an increase in requirements of developing renewable electricity. Various types of solar cells including inorganic solar cells, dye-sensitized solar cells and organic solar cells have been developed. Apart from the study on the materials for solar cells, the study on nano- and micro-structures for solar cells has been greatly noticed since novel nano- and micro-structures are very useful to enhance the efficiency of solar cells. There are two approaches for utilizing nanoand micro-structures to enhance the efficiency of solar cells. One is reducing the reflection of incident light at the interface between a solar cell and air. Another one is increasing the light trapping inside a solar cell. Especially, trapping the light inside the solar cell is largely important to enhance the light absorption in thin film solar cell structures. Both approaches focus the elevation of absorbing and harvesting the light of the Sun inside a solar cell. Our group has developed the fabrication process of anti-reflection nano-structure for solar cells using NIL [185-192]. The polymer-based moth-eye structures were formed on the protective layer of a thin film solar cell and on the top surface of a GaAs solar cell by UV NIL. The SEM micrograph of Figure 21a shows the moth-eye pattern on the glass substrate [188]. Solar cells are usually exposed to external shock, heat, UV irradiation and corrosive acidic rain, since they are installed outdoors in order to absorb the light of the sun. Thus, protection layers which are mainly made of glass cover the solar cells to protect from harsh outdoor conditions. However, the conversion efficiency of the solar cell is limited due 
to the reflection of incident light on the protective layer. In our works, the total conversion efficiencies of all solar cells with the moth-eye pattern were increased, since the moth-eye patterns reduced the reflection of the light at the protective layer/air interface and top solar cell layer/air interface. Recently, we developed moth-eye patterned protection glass which has high mechanical strength and low surface energy as well as high transmittance [189]. High mechanical strength of the anti-reflection layer is needed to endure physical and chemical shock, and low surface energy of the anti-reflection layer is also needed for selfcleaning of dust and dirt by rain. In this work, the mixture of methacryloxypropyl-terminated polydimethysiloxane (M-PDMS) and a photo-initiator is used as a UV imprint resist. The moth-eye pattern was fabricated on the protection glass by UV NIL with a flexible polymer mold and M-PDMS-based resin. The hardness and modulus of M-PDMS were several hundred times greater than commercially available resist (NIP-K28 ${ }^{\mathrm{TM}}$ ), and the glass with the moth-eye pattern showed higher transmittance than that of the glass without the moth-eye patterns. To achieve the low surface energy of M-PDMS-based motheye pattern, the surface of the M-PDMS pattern was break exposed to oxygen plasma to generate $\mathrm{OH}$ for stable covalent bonding with the hydrophobic SAM layer. Then a heptadecafluoro-1,1,2,2-tetrahydrodecyl trichlorosilanebased SAM was directly formed on the M-PDMS motheye pattern. As a result, the contact angle of a DI water droplet on the M-PDMS moth-eye pattern was above $130^{\circ}$. Figure $21 \mathrm{~b}$ shows the charge capacity of batteries connected to the solar cells with/without the motheye patterns, placed outdoors. We confirmed that the solar cells with the moth-eye patterned protection glass generated more electricity than the solar cells without moth-eye patterned protection glass by the improved transmittance and the low surface energy of the patterned protection glass.

NIL has been recently employed to fabricate lighttrapping structures in solar cells. Bessonov et al. developed a thin film Si solar cell having randomly textured front glass by UV NIL [193]. They first fabricated mater templates having randomly distributed pyramidal features with typical lateral sizes of around $400 \mathrm{~nm}$ and $1100 \mathrm{~nm}$ by natural growth of $\mathrm{ZnO}: \mathrm{B}$ on a glass substrate using low pressure chemical vapor deposition. Then the features of the mater templates were transferred on the front glass of the solar cell by UV imprinting using a urethane acrylatebased resin. To smooth the features on the glass substrate for preventing the generation of cracks on the solar cell structure, they repeatedly replicated the patterned glass substrate using pre-replicated patterned glass. Based on the patterned and unpatterned glass substrates, micromorph tandem thin film Si solar cells were fabricated. They confirmed that the highest efficiency was obtained when the smoothly patterned glass was used in the solar cell as the front glass. Escarré et al. [194] also developed similar work. They fabricated the patterned front glass for the $n$ - $i$ - $p$ thin film solar cell and the patterned back glass of the $p$ - $i$ - $n$ thin film glass with micron scale using UV NIL. Solar cells with the patterned glass substrates showed

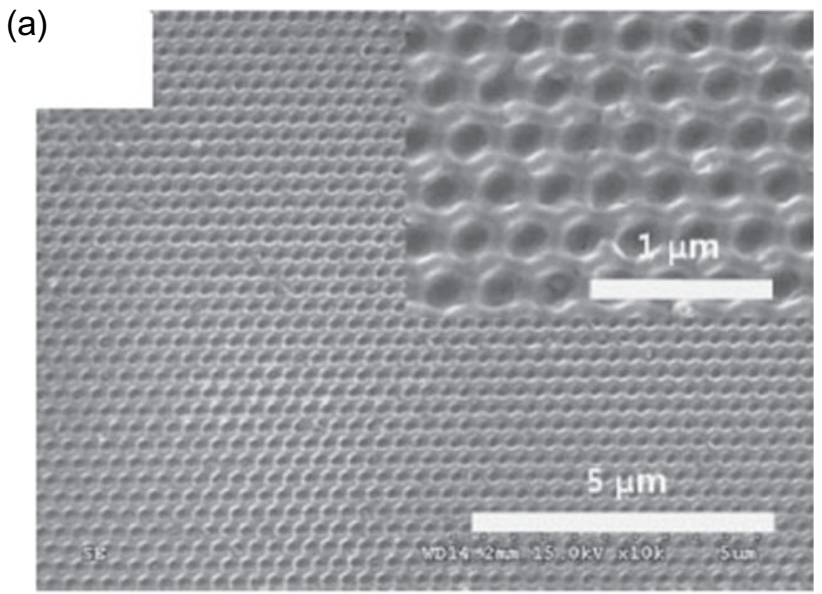

(b)

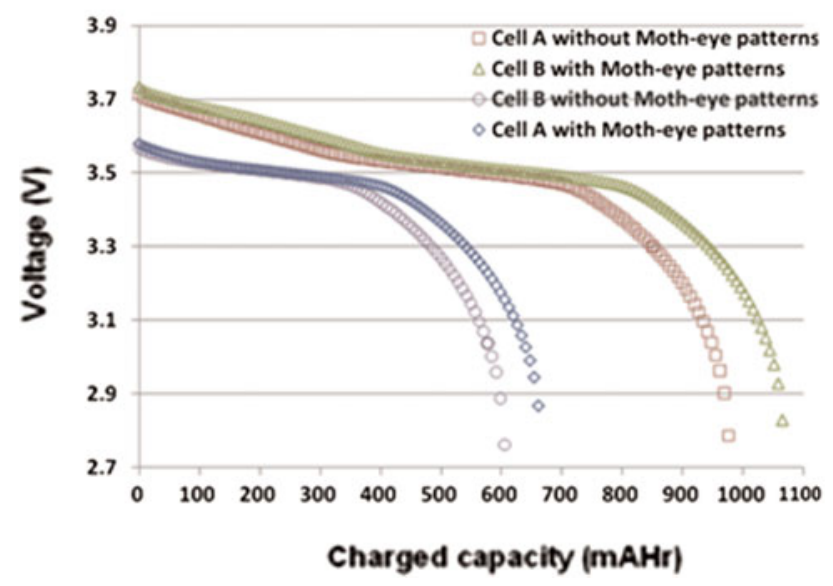

Fig. 21. (Color online) (a) The imprinted moth-eye pattern on the glass substrate. Reproduced with permission from reference [188]. Copyright 2011, The Japan Society of Applied Physics. (b) Charge capacity of batteries connected to photovoltaic systems with/without moth-eye patterns. Reprinted with permission from reference [189]. Copyright 2010, John Wiley and Sons.

higher conversion efficiency than solar cells without patterned glass substrate. However, polymeric materials with low modulus and low thermal stability were used as a light trapping layer for the solar cells. In recent years, Ferry et al. [195] developed a direct NIL process using a silica sol for fabricating the back glass substrate with light trapping structures. In their work, the silica sol was coated on the glass substrate and was imprinted with the PDMS mold at room temperature. During the imprinting process, the silica sol-gel layer was solidified by forming a silica network while sol-gel reaction products were absorbed and diffused into the PDMS mold. Afterwards, the glass substrate with silica sol-gel pattern was cured at $200{ }^{\circ} \mathrm{C}$. Next, they fabricated Si thin film solar cells on the patterned glass substrates which included a periodic array of sub-micron dots randomly distributed sub-micron dots, and Asahi U-type texture which is commercially available for solar cells. Figures 22a and 22b show the schematic diagram and tilted SEM micrograph of the thin film solar 
(a)

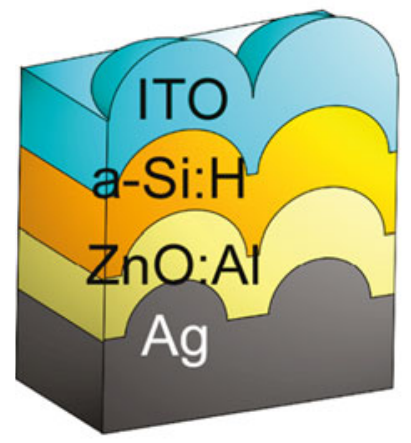

(b)

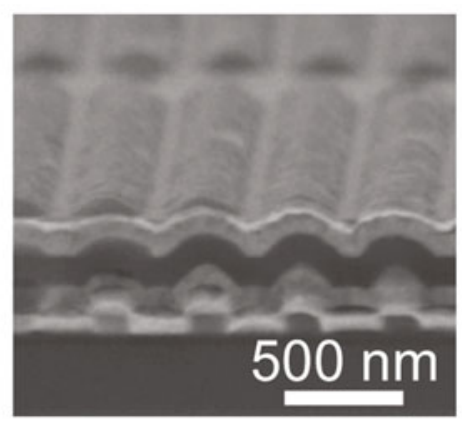

(c)

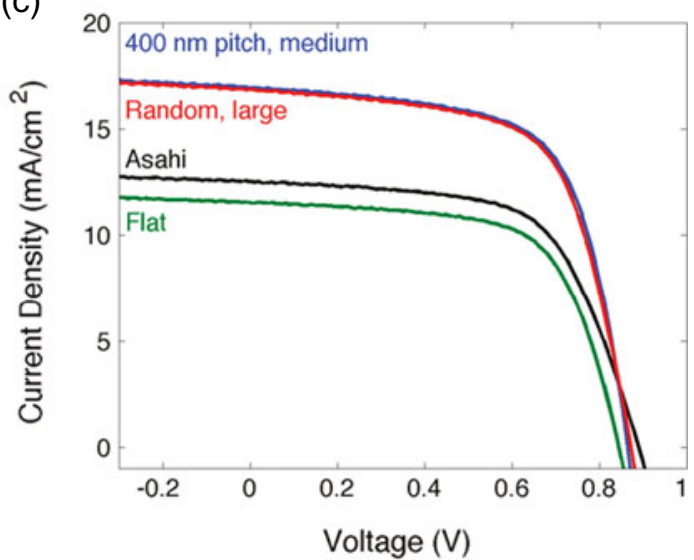

Fig. 22. (Color online) Current density-voltage measurements of nano-patterned cells. The cells are conformally deposited over the patterned substrate, as shown schematically in (a) and in SEM cross-section ( $5^{\circ}$ angle) in (b). The maximum particle diameter in the backpattern was chosen so that nano-structures in the ITO top layer would touch without overlap. (c) Current density-voltage measurements for the best-efficiency cells on the substrate with $90 \mathrm{~nm}$ intrinsic layers. The optimized periodic pattern and the pseudorandom pattern have efficiencies of $9.6 \%$ and $9.4 \%$, respectively. Reproduced with permission from reference [195]. Copyright 2011, American Chemical Society.

cell structure on the patterned glass substrate. As shown in the current density-voltage measurements of Figure 22c, they confirmed that the solar cell with the optimized periodic patterned and the pseudorandom patterned glass substrates had higher efficiency than the solar cell with Asahi U-type texture. This is a greatly meaningful result which demonstrates the usefulness of the direct NIL process for solar cells.

In recent years, many studies to increase the efficiency of organic solar cells by NIL have been conducted. In these studies, the active layer of the organic solar cell was directly patterned with various nano- and micro-structures by NIL. In organic solar cells, electrons and holes are generated at the interface between the donor layer and the acceptor layer, and they move into respective electrodes. However, the diffusion length of the electrons is limited to $\sim 10 \mathrm{~nm}$ before decaying to the ground state in the conjugated polymer of organic solar cell structure [196]. Therefore, increasing the donor/acceptor interfacial area and reducing the active layer morphology are significantly important to achieve high efficiency. Nano-patterned active layers of organic solar cells fulfill these requirements for achieving high efficiency. Since the active layer of an organic solar cell is mostly polymeric material, it can be patterned with nano-structures by NIL. Cheyns et al. [197] demonstrated high efficiency organic solar cell with an imprinted poly(3-hexylthiophene) (P3HT) layer. He et al. [198] fabricated double-imprinted heterojunction organic solar cells. In their work, the anode layer for P3HT:[6,6]-phenyl-C61-butyric acid methyl ester (PCBM) devices and the cathode layer for poly((9,9-dioctylfluorene),2,7-diyl-alt-[4,7-bis(3-hexylthien-5-yl)2,1,3-benzothiadiazole]-2', $2^{\prime \prime}$-diyl) (F8TBT):PCBM were firstly imprinted with an Si mold, and the imprinted layers were used as a mold to imprint the second film, resulting in a double-imprinted solar cell. Chen et al. [199] also developed an organic solar cell with imprinted P3HT an- ode layer. To achieve nano-scaled structure on the P3HT layer, an AAO was used to fabricate the P3HT nanopillar in a thermal imprinting process. As a result, they confirmed that the P3HT nanopillar structures increased the interfacial area of the $\mathrm{P} 3 \mathrm{HT} / \mathrm{PCBM}$ heterojunction and enhanced the efficiency to around $2.4 \%$.

\section{Conclusion and summary}

NIL is an efficient nano-patterning technology that can fabricate various micro- and nano-structures with high throughput, high resolution and low cost. Conventional NIL technology is an indirect patterning process similar to photolithography which requires deposition, formation of resist pattern and substrate etching or lift-off. Therefore, the throughput on the fabrication of functional materials is limited by multi-process steps. To overcome this limitation, several direct patterning processes have been proposed. Among them, NIL-based direct patterning technology has attracted great interest due to its capability for mass production and usefulness of various applications. Recent progress on direct NIL using functional resins, such as sol-gel solutions, nanoparticles solution, nanoparticle-dispersed resins and SOG, has enabled direct fabrication of functional micro- and nano-structures which consist of inorganic and organic-inorganic hybrid materials with simple process steps and without harsh process conditions. According to these advantages, NIL-based direct patterning processes have been applied to diverse devices for the enhancement of their performance. Furthermore, NIL-based direct patterning process can be combined with bottom-up nano-fabrication techniques, such as block copolymer lithography [200-203] and nanorod growth [204-207], to overcome size limitation that is determined with the minimum feature size of the master imprint stamp. We suggest the bottom-up hybrid NIL 
process as one of the future nano-fabrication technologies for realizing next-generation nano-devices which need sub$20 \mathrm{~nm}$ functional nano-structures, such as nanochannelbased field effect transistor, nanophotonic devices, nano-optical sensor, nanorod-based optoelectronic devices. In this review, we introduced that the overall efficiency of organic and inorganic-based electronic devices including LEDs, OLEDs and solar cells was enhanced by inserting nano- and micro-structures into the devices. We expect that the application fields of NIL will continue to grow, and that the NIL-based direct patterning process is one of the most promising patterning technologies to enhance the performance of various devices.

This research was supported by Basic Science Research Program through the National Research Foundation of Korea(NRF) funded by the Ministry of Education, Science and Technology (2010-0011363). This research was also supported by Technology Innovation Program funded by the Ministry of Knowledge Economy (20103020010020-11-2-100).

\section{References}

1. Y. Mimura, T. Ohkubo, T. Takeuchi, K. Sekikawa, Jpn J. Appl. Phys. 17, 541 (1978)

2. Y. Kawamura, K. Toyoda, S. Namba, Appl. Phys. Lett. 40, 374 (1982)

3. B.G. Burke, T.J. Herlihy Jr., A.B. Spisak, K.A. Williams, Nanotechnology 19, 215301 (2008)

4. M. Zheng, M. Yu, Y. Liu, R. Skomski, S.H. Liou, D.J. Sellmyer, V.N. Petryakov, Yu.K. Verevkin, N.I. Polushkin, N.N. Salashchenko, Appl. Phys. Lett. 79, 2606 (2001)

5. I. Divliansky, T.S. Mayer, K.S. Holliday, V.H. Crespi, Appl. Phys. Lett. 82, 1667 (2003)

6. A. Fernandez, J.Y. Decker, S.M. Herman, D.W. Phillion, D.W. Sweeney, M.D. Perry, J. Vac. Sci. Technol. B 15, 2439 (1997)

7. J.C. Hulteen, R.P. Van Duyne, J. Vac. Sci. Technol. A 13, 1553 (1995)

8. C.L. Haynes, R.P. Van Duyne, J. Phys. Chem. B 105, $5599(2001)$

9. J.-Y. Shiu, C.-W. Kuo, P. Chen, C.-Y. Mou, Chem. Mater. 16, 561 (2004)

10. M. Park, C. Harrison, P.M. Chaikin, R.A. Register, D.H. Adamson, Science 276, 1401 (1997)

11. J.Y. Cheng, C.A. Ross, V.Z.-H. Chan, E.L. Thomas, R.G.H. Lammertink, G.J. Vancso, Adv. Mat. 13, 1174 (2001)

12. C. Tang, E.M. Lennon, G.H. Fredrickson, E.J. Kramer, C.J. Hawker, Science 322, 429 (2008)

13. S.Y. Chou, P.R. Krauss, P.J. Renstrom, Appl. Phys. Lett. 67, 3114 (1995)

14. T. Bailey, B.J. Choi, M. Colburn, M. Meissl, S. Shaya, J.G. Ekerdt, S.V. Sreenivasan, C.G. Willson, J. Vac. Sci. Technol. B 18, 3572 (2000)

15. H. Lee, G.Y. Jung, Microelectron. Eng. 77, 42 (2005)

16. H. Lee, G.Y. Jung, Microelectron. Eng. 77, 168 (2005)

17. H. Lee, S. Hong, K. Yang, K. Choi, Appl. Phys. Lett. 88, $143112(2006)$
18. J.-H. Shin, K.-Y. Yang, K.-S. Han, H.-S. Kim, H. Lee, J. Nanosci. Nanotechnol. 12, 3364 (2012)

19. S.-H. Hong, K.-S. Han, H. Lee, J.U. Cho, Y.K. Kim, Jpn J. Appl. Phys. 46, 6375 (2007)

20. H.Y. Jung, S.Y. Hwang, B.J. Bae, H. Lee, J. Vac. Sci. Technol. B 27, 1861 (2009)

21. R.D. Piner, J. Zhu, F. Xu, S. Hong, C.A. Mirkin, Science 283, 661 (1999)

22. B.W. Maynor, Y. Li, J. Liu, Langmuir 17, 2575 (2001)

23. S. Park, H.W. Lee, H. Wang, S. Selvarasah, M.R. Dokmeci, Y.J. Park, S.N. Cha, J.M. Kim, Z. Bao, ACS Nano 6, 2487 (2012)

24. M. Pudas, J. Hagberg, S. Leppävuori, J. Eur. Ceram. Soc. 24, $2943(2004)$

25. W.-X. Huang, S.-H. Lee, H.J. Sung, T.-M. Lee, D.-S. Kim, Int. J. Heat Fluid Flow 29, 1436 (2008)

26. T.-M. Lee, S.-H. Lee, J.-H. Noh, D.-S. Kim, S. Chun, J. Micromech. Microeng. 20, 125026 (2010)

27. C.W. Sele, T. von Werne, R.H. Friend, H. Sirringhaus, Adv. Mat. 17, 997 (2005)

28. H. Sirringhaus, T. Kawase, R.H. Friend, T. Shimoda, M. Inbasekaran, W. Wu, E.P. Woo, Science 290, $2123(2000)$

29. M. Singh, H.M. Haverinen, P. Dhagat, G.E. Jabbour, Adv. Mat. 22, 673 (2010)

30. S.Y. Chou, P.R. Krauss, W. Zhang, L. Guo, L. Zhuang, J. Vac. Sci. Technol. B 15, 2897 (1997)

31. M.D. Austin, H. Ge, W. Wu, M. Li, Z. Yu, D. Wasserman, S.A. Lyon, S.Y. Chou, Appl. Phys. Lett. 84, 5299 (2004)

32. H. Lee, J. Vac. Sci. Technol. B 23, 1102 (2005)

33. H. Lee, G.Y. Jung, Jpn J. Appl. Phys. 43, 8369 (2004)

34. K.-Y. Yang, J.-W. Kim, K.-J. Byeon, H.-C. Lee, H. Lee, J. Nanosci. Nanotechnol. 9, 4194 (2009)

35. K.-Y. Yang, K.-M. Yoon, J.-W. Kim, J.-H. Lee, H. Lee, Jpn J. Appl. Phys. 48, 095003 (2009)

36. J.-H. Lee, K.-Y. Yang, S.-H. Hong, H. Lee, K.-W. Choi, Microelectron. Eng. 85, 710 (2008)

37. K.-J. Byeon, K.-Y. Yang, H. Lee, Microelectron. Eng. 84, 1003 (2007)

38. K.-Y. Yang, J.-W. Kim, K.-J. Byeon, H. Lee, Microelectron. Eng. 84, 1552 (2007)

39. S.Y. Chou, C. Keimel, J. Gu, Nature 417, 835 (2002)

40. S.C. Oh, B.J. Bae, K.Y. Yang, M.H. Kwon, H. Lee, Met. Mater. Int. 17, 771 (2011)

41. J. Taniguchi, Y. Tokano, I. Miyamoto, M. Komuro, H. Hiroshima, Nanotechnology 13, 592 (2002)

42. U. Plachetka, M. Bender, A. Fuchs, B. Vratzov, T. Glinsner, F. Lindner, H. Kurz, Microelectron. Eng. 73-74, 167 (2003)

43. V. Malyarchuk, F. Hua, N.H. Mack, V.T. Velasquez, J.O. White, R.G. Nuzzo, J.A. Rogers, Optic. Express 13, 5669 (2005)

44. N. Koo, M. Bender, U. Plachetka, A. Fuchs, T. Wahlbrink, J. Bolten, H. Kurz, Microelectron. Eng. 84, $904(2007)$

45. I.W. Moran, A.L. Briseno, S. Loser, K.R. Carter, Chem. Mater. 20, 4595 (2008)

46. J.-W. Kim, K.-Y. Yang, S.-H. Hong, H. Lee, Appl. Surf. Sci. 254, 5607 (2008)

47. J. Zaumseil, M.A. Meitl, J.W.P. Hsu, B.R. Acharya, K.W. Baldwin, Y.-L. Loo, J.A. Rogers, Nano Lett. 3, 1223 (2003) 
48. K. Felmet, Y.-L. Loo, Y. Sun, Appl. Phys. Lett. 85, 3316 (2004)

49. N. Kehagias, V. Reboud, G. Chansin, M. Zelsmann, C. Jeppesen, C. Schuster, M. Kubenz, F. Reuther, G. Gruetzner, C.M.S. Torres, Nanotechnology 18, 175303 (2007)

50. H.Y. Jung, K.-S. Han, J.H. Lee, H. Lee, J. Nanosci. Nanotechnol. 9, 4338 (2009)

51. Y. Xia, G.M. Whitesides, Annu. Rev. Mater. Sci. 28, 153 (1998)

52. H.-W. Li, B.V.O. Muir, G. Fichet, W.T.S. Huck, Langmuir 19, 1963 (2003)

53. Y. Chen, A. Lebib, S. Li, A. Pépin, D. Peyrade, M. Natali, E. Cambril, Eur. Phys. J. Appl. Phys. 12, 223 (2000)

54. Y.-T. Hsieh, Y.-C. Lee, J. Micromech. Microeng. 21, $015001(2011)$

55. M.H. Lee, J.Y. Lin, T.W. Odom, Angew. Chem. 122 , $3121(2010)$

56. J.-H. Shin, S.-H. Lee, K.-J. Byeon, K.-S. Han, H. Lee, K. Tsunozaki, Nanoscale Res. Lett. 6, 458 (2011)

57. S.-H. Hong, J.-Y. Hwang, H. Lee, H.-C. Lee, K.-W. Choi, Microelectron. Eng. 86, 295 (2009)

58. S.-H. Hong, J. Hwang, H. Lee, Nanotechnology 20 $385303(2009)$

59. J. Hwang, S.-H. Hong, H. Lee, J. Nanosci. Nanotechnol. 9, $3644(2009)$

60. S.-H. Hong, B.-J. Bae, J.-Y. Hwang, S.-Y. Hwang, H. Lee, Microelectron. Eng. 86, 2423 (2009)

61. Y. Sun, J.H. Seo, C.J. Takacs, J. Seifter, A.J. Heeger, Adv. Mat. 23, 1679 (2011)

62. A. Elfanaoui, E. Elhamri, L. Boulkaddat, A. Ihlal, K. Bouabid, L. Laanab, A. Taleb, X. Portier, Int. J. Hydrogen Energy 36, 4130 (2011)

63. H. Cho, Y.-H. Yun, Ceram. Int. 37, 615 (2011)

64. H. Wang, M.-H. Xu, J.-W. Xu, M.-F. Ren, L. Yang, J. Mater. Sci.: Mater. Electron. 21, 589 (2010)

65. D.M. Carvalho, J.L.B. Maciel, L.P. Ravaro, R.E. Garcia, V.G. Ferreira, L.V.A. Scalvi, J. Sol-Gel Sci. Technol. 55, $385(2010)$

66. H. Kim, P.A. Kohl, J. Power Sources 195, 2224 (2010)

67. B. Weintraub, Z. Zhou, Y. Li, Y. Deng, Nanoscale 2, 1573 (2010)

68. C. Shang, Z.-P. Liu, J. Am. Chem. Soc. 133, 9938 (2011)

69. C. Levard, B.C. Reinsch, F.M. Miche, C. Oumahi, G.V. Lowry, G.E. Brown Jr., Environ. Sci. Technol. 45, 5260 (2011)

70. Z. Ji, X. Jin, S. George, T. Xia, H. Meng, X. Wang, E. Suarez, H. Zhang, E.M.V. Hoek, H. Godwin, A.E. Nel, J.I. Zink, Environ. Sci. Technol. 44, 7309 (2010)

71. C.O. Metin, L.W. Lake, C.R. Miranda, Q.P. Nguyen, J. Nanopart. Res. 13, 839 (2011)

72. J. Zhu, S. Wei, J. Ryu, L. Sun, Z. Luo, Z. Guo, ACS Appl. Mater. Int. 2, 2100 (2010)

73. T. Agag, T. Takeichi, Polymer 52, 2757 (2011)

74. Y.J. Kim, S.Y. Park, J.J. Lee, J. Nanosci. Nanotechnol. 10, $3232(2010)$

75. I. Jung, Y.H. Jo, I. Kim, H.M. Lee, J. Electron. Mater. 41, 115 (2012)

76. B.T. Anto, S. Sivaramakrishnan, L.-L. Chua, P.K.H. Ho, Adv. Funct. Mater. 20, 296 (2010)

77. R. Shankar, L. Groven, A. Amert, K.W. Whites, J.J. Kellar, J. Mater. Chem. 21, 10871 (2011)
78. J. Kim, S.-I. Na, H.-K. Kim, Solar Energy Mater. Solar Cells 98, 424 (2012)

79. J. Yao, A.-P. Le, M.V. Schulmerich, J. Maria, T.-W. Lee, S.K. Gray, R. Bhargava, J.A. Rogers, R.G. Nuzzo, ACS Nano 5, 5763 (2011)

80. G.M. Schmid, M.D. Stewart, J. Wetzel, F. Palmieri, J.J. Hao, Y. Nishimura, K. Jen, E.K. Kim, D.J. Resnick, J.A. Liddle, C.G. Willson, J. Vac. Sci. Technol. B 24, 1283 (2006)

81. S. Bizet, J. Galy, J.-F. Gerard, Macromolecules 39, 2574 (2006)

82. A. Cattoni, E. Cambril, D. Decanini, G. Faini, A.M. Haghiri-Gosnet, Microelectron. Eng. 87, 1015 (2010)

83. C.G. Gamys, E. Beyou, E. Bourgeat-Lami, J. Polym. Sci. Polym. Chem. 48, 784 (2010)

84. G. Yu, L. Zhu, X. Wang, J. Liu, D. Xu, Micropor. Mesopor. Mater. 130, 189 (2010)

85. N. Hagura, W. Widiyastuti, F. Iskandar, K. Okuyam, Chem. Eng. J. 156, 200 (2010)

86. S. Dirè, V. Tagliazucca, E. Callone, A. Quaranta, Mater. Chem. Phys. 126, 909 (2011)

87. M. Bender, U. Plachetka, J. Ran, A. Fuchs, B. Vratzov, H. Kurz, T. Glinsner, F. Lindner, J. Vac. Sci. Technol. B 22, 3229 (2004)

88. F. Peng, J. Liu, J. Li, J. Membr. Sci. 222, 225 (2003)

89. S. Mishima, H. Kaneoka, T. Nakagawa, J. Appl. Polym. Sci. 71, 273 (1999)

90. S.-J. Choi, P.J. Yoo, S.J. Baek, T.W. Kim, H.H. Lee, J. Am. Chem. Soc. 126, 7744 (2004)

91. E. Kim, Y. Xia, G.M. Whitesides, J. Am. Chem. Soc. 118, 5722 (1996)

92. K.S. Han, S.H. Hong, H. Lee, Appl. Phys. Lett. 91, 123118 (2007)

93. K.-S. Han, S.-H. Hong, J.-H. Jeong, H. Lee, Microelectron. Eng. 87, 610 (2010)

94. X.D. Huang, L.-R. Bao, X. Cheng, L.J. Guo, S.W. Pang, A.F. Yee, J. Vac. Sci. Technol. B 20, 2872 (2002)

95. M. Li, H. Tan, L. Chen, J. Wang, S.Y. Chou, J. Vac. Sci. Technol. B 21, 660 (2003)

96. K.-M. Yoon, K.-Y. Yang, H. Lee, Thin Solid Films 518, $126(2009)$

97. L.M. Campos, I. Meinel, R.G. Guino, M. Schierhorn, N. Gupta, G.D. Stucky, C.J. Hawker, Adv. Mat. 20, 3728 (2008)

98. I.W. Moran, D.F. Cheng, S.B. Jhaveri, K.R. Carter, Soft Matt. 4, 168 (2008)

99. K.-Y. Yang, K.-M. Yoon, K.-W. Choi, H. Lee, Microelectron. Eng. 86, 2228 (2009)

100. K.-M. Yoon, K.-Y. Yang, H. Lee, H.-S. Kim, J. Vac. Sci. Technol. B 27, 2810 (2009)

101. C. Goh, K.M. Coakley, M.D. McGehee, Nano Lett. 5, $1545(2005)$

102. R. Ganesan, J. Dumond, M.S.M. Saifullah, S.H. Lim, H. Hussain, H.Y. Low, ACS Nano 6, 1494 (2012)

103. P.C. Hidber, W. Helbig, E. Kim, G.M. Whitesides, Langmuir 12, 1375 (1996)

104. V. Santhanam, R.P. Andres, Nano Lett. 4, 41 (2004)

105. T. Kraus, L. Malaquin, H. Schmid, W. Riess, N.D. Spencer, H. Wolf, Nature Nanotechnol. 2, 570 (2007)

106. T.H.J. van Osch, J. Perelaer, A.W.M. de Laat, U.S. Schubert, Adv. Mat. 20, 343 (2008) 
107. E. Tekin, P.J. Smith, U.S. Schubert, Soft Matt. 4, 703 (2008)

108. Y. Lee, J.-R. Choi, K.J. Lee, N.E. Stott, D. Kim, Nanotechnology 19, 415604 (2008)

109. F.C. Krebs, M. Jørgensen, K. Norrman, O. Hagemann, J. Alstrup, T.D. Nielsen, J. Fyenbo, K. Larsen, J. Kristensen, Solar Energy Mater. Solar Cells 93, 422 (2009)

110. F.C. Krebs, J. Fyenbo, M. Jørgensen, J. Mater. Chem. 20, 8994 (2010)

111. A. Sánchez, S. Morante-Zarcero, D. Pérez-Quintanilla, I. Sierra, I. del Hierro, Electrochim. Acta 55, 6983 (2010)

112. S.H. Ko, I. Park, H. Pan, C.P. Grigoropoulos, A.P. Pisano, C.K. Luscombe, J.M.J. Fréchet, Nano Lett. 7, 1869 (2007)

113. K.-Y. Yang, K.-M. Yoon, S. Lim, H. Lee, J. Vac. Sci. Technol. B 27, 2786 (2009)

114. M.J. Hampton, J.L. Templeton, J.M. DeSimone, Langmuir 26, 3012 (2010)

115. H.-H. Park, D.-G. Choi, X. Zhang, S. Jeon, S.-J. Park, S.-W. Lee, S. Kim, K.-D. Kim, J.-H. Choi, J. Lee, D.K. Yun, K.J. Lee, H.-H. Park, R.H. Hill, J.-H. Jeong, J. Mater. Chem. 20, 1921 (2010)

116. S.H. Lim, M.S.M. Saifullah, H. Hussain, W.W. Loh, H.Y. Low, Nanotechnology 21, 285303 (2010)

117. J.H. Choi, S.W. Lee, K.D. Kim, D.G. Choi, J.H. Jeong, E.S. Lee, Curr. App. Phys. 9, S138 (2009)

118. J.-H. Choi, S.-W. Lee, J.-H. Jeong, D.-G. Choi, J.-H. Lee, E.-S. Lee, Jpn J. Appl. Phys. 48, 06FH02 (2009)

119. P. Wang, J. Guo, H. Wang, Y. Zhang, J. Wei, J. Phys. Chem. C 113, 8118 (2009)

120. J.-H. Choi, S.-W. Lee, D.-G. Choi, K.-D. Kim, J.-H. Jeong, E.-S. Lee, J. Vac. Sci. Technol. B 26, 1390 (2008)

121. S. Matsui, Y. Igaku, H. Ishigaki, J. Fujita, M. Ishida, Y. Ochiai, M. Komuro, H. Hiroshima, J. Vac. Sci. Technol. B 19, 2801 (2001)

122. Y. Igaku, S. Matsui, H. Ishigaki, J. Fujita, M. Ishida, Y. Ochiai, H. Namatsu, M. Komuro, H. Hiroshima, Jpn J. Appl. Phys. 41, 4198 (2002)

123. Y. Kang, M. Okada, C. Minari, K. Kanda, Y. Haruyama, S. Matsui, Jpn J. Appl. Phys. 49, 06GL13 (2010)

124. K.-I. Nakamatsu, K. Watanabe, K. Tone, H. Namatsu, S. Matsui, J. Vac. Sci. Technol. B 23, 507 (2005)

125. H.W. Ro, H. Peng, K.-I. Niihara, H.-J. Lee, E.K. Lin, A. Karim, D.W. Gidley, H. Jinnai, D.Y. Yoon, C.L. Soles, Adv. Mat. 20, 1934 (2008)

126. M. Okinaka, K. Tsukagoshi, Y. Aoyagi, J. Vac. Sci. Technol. B 24, 1402 (2006)

127. K.-Y. Yang, S.-C. Oh, H. Park, H. Lee, J. Vac. Sci. Technol. B 29, 051602 (2011)

128. S.Y. Hwang, H.Y. Jung, J.-H. Jeong, H. Lee, Thin Solid Films 517, 4104 (2009)

129. S.-Y. Hwang, S.-H. Hong, H.-Y. Jung, H. Lee, Microelectron. Eng. 86, 642 (2009)

130. S.-H. Hong, K.-S. Han, K.-J. Byeon, H. Lee, K.-W. Choi, Jpn J. Appl. Phys. 47, 3699 (2008)

131. S.-H. Hong, J.-H. Jeong, K.-I. Kim, H. Lee, Microelectron. Eng. 88, 2013 (2011)

132. K.-I. Kim, K.-S. Han, K.-Y. Yang, H.-S. Kim, H. Lee, J. Nanosci. Nanotechnol. 12, 3417 (2012)

133. H. Lee, S. Hong, K. Yang, K. Choi, Microelectron. Eng. 83, 323 (2006)
134. H.J.H. Chen, J.-R. Jhang, C.-J. Huang, S.-Z. Chen, J.-C. Huang, IEEE Electron Device Lett. 32, 155 (2011)

135. J.-G. Kim, Y. Sim, Y. Cho, J.-W. Seo, S. Kwon, J.-W. Park, H.G. Choi, H. Kim, S. Lee, Microelectron. Eng. 86, 2427 (2009)

136. B.-K. Choo, J.-S. Choi, S.-W. Kim, K.-C. Park, J. Jang, J. Non-Cryst. Solids 352, 1704 (2006)

137. D. Cui, H. Li, H. Park, X. Cheng, J. Vac. Sci. Technol. B 26, 2404 (2008)

138. C. Auner, U. Palfinger, H. Gold, J. Kraxner, A. Haase, T. Haber, M. Sezen, W. Grogger, G. Jakopic, J.R. Krenn, G. Leising, B. Stadlober, Org. Electr. 10, 1466 (2009)

139. B. Stadlober, U. Haas, H. Gold, A. Haase, G. Jakopic, G. Leising, N. Koch, S. Rentenberger, E. Zojer, Adv. Funct. Mater. 17, 2687 (2007)

140. W.-D. Li, S.Y. Chou, Optic. Express 18, 931 (2010)

141. S.-W. Ahn, K.-D. Lee, J.-S. Kim, S.H. Kim, J.-D. Park, S.-H. Lee, P.-W. Yoon, Nanotechnology 16, 1874 (2005)

142. S.H. Kim, J.-D. Park, K.-D. Lee, Nanotechnology 17, $4436(2006)$

143. K.-J. Byeon, S.-Y. Hwang, H. Lee, Appl. Phys. Lett. 91 , $091106(2007)$

144. J.-Y. Kim, M.-K. Kwon, K.-S. Lee, S.-J. Park, S.H. Kim, K.-D. Lee, Appl. Phys. Lett. 91, 181109 (2007)

145. M.-G. Kang, L.J. Guo, Adv. Mat. 19, 1391 (2007)

146. S. Jeon, J.-W. Kang, H.-D. Park, J.-J. Kim, J.R. Youn, J. Shim, J.-H. Jeong, D.-G. Choi, K.-D. Kim, A.O. Altun, S.-H. Kim, Y.-H. Lee, Appl. Phys. Lett. 92, 223307 (2008)

147. K.-J. Byeon, E.-J. Hong, H. Park, J.-Y. Cho, S.-H. Lee, J. Jhin, J.H. Baek, H. Lee, Thin Solid Films 519, 2241 (2011)

148. K.-J. Byeon, J.-Y. Cho, J. Kim, H. Park, H. Lee, Optic. Express 20, 11423 (2012)

149. E.-J. Hong, K.-J. Byeon, H. Park, J. Hwang, H. Lee, K. Choi, H.-S. Kim, Solid-State Electron. 53, 1099 (2009)

150. K.-J. Byeon, H. Park, J.-Y. Cho, S.-H. Lee, S.Y. Lee, J.O. Song, H. Lee, Curr. App. Phys. 11, S147 (2011)

151. H. Park, K.-J. Byeon, J.-J. Jang, O. Nam, H. Lee, Microelectron. Eng. 88, 3207 (2011)

152. J.-Y. Cho, K.-J. Byeon, H. Park, H.-S. Kim, H. Lee, Jpn J. Appl. Phys. 49, 102103 (2010)

153. O. Hellwig, J.K. Bosworth, E. Dobisz, D. Kercher, T. Hauet, G. Zeltzer, J.D. Risner-Jamtgaard, D. Yaney, R. Ruiz, Appl. Phys. Lett. 96, 052511 (2010)

154. Q. Dong, G. Li, C.-L. Ho, M. Faisal, C.-W. Leung, P.W.-T. Pong, K. Liu, B.-Z. Tang, I. Manners, W.-Y. Wong, Adv. Mat. 24, 1034 (2012)

155. S.-H. Hong, H. Lee, Y. Choi, Y.-K. Lee, Curr. App. Phys. 11, S16 (2011)

156. B.-J. Bae, S.-H. Hong, S.-Y. Hwang, J.-Y. Hwang, K.-Y. Yang, H. Lee, Semicond. Sci. Technol. 24, 075016 (2009)

157. S.-H. Hong, B.-J. Bae, H. Lee, J.-H. Jeong, Microelectron. Eng. 87, 2081 (2010)

158. M. Meier, S. Gilles, R. Rosezin, C. Schindler, S. Trellenkamp, A. Rüdiger, D. Mayer, C. Kügeler, R. Waser, Microelectron. Eng. 86, 1060 (2009)

159. H.Y. Jeong, J.Y. Lee, S.-Y. Choi, Adv. Funct. Mater. 20, 3912 (2010)

160. K.-Y. Yang, J.-W. Kim, S.-H. Hong, J.-Y. Hwang, H. Lee, Thin Solid Films 518, 5662 (2010) 
K.-J. Byeon and H. Lee: Recent progress in direct patterning technologies based on nano-imprint lithography

161. K.-Y. Yang, S.-H. Hong, D.-K. Kim, B.-K. Cheong, H. Lee, Microelectron. Eng. 84, 21 (2007)

162. H. Lee, S.-H. Hong, K.-Y. Yang, G.-Y. Jung, Microelectron. Eng. 84, 573 (2007)

163. S.-H. Hong, B.-J. Bae, H. Lee, Nanotechnology 21, $025703(2010)$

164. D.-H. Ko, J.R. Tumbleston, A. Gadisa, M. Aryal, Y. Liu, R. Lopez, E.T. Samulski, J. Mater. Chem. 21, 16293 (2011)

165. W. Zeng, K.S.L. Chong, H.Y. Low, E.L. Williams, T.L. Tam, A. Sellinger, Thin Solid Films 517, 6833 (2009)

166. C. Battaglia, J. Escarre, K. Söderström, L. Erni, L. Ding, G. Bugnon, A. Billet, M. Boccard, L. Barraud, S. De Wolf, F.-J. Haug, M. Despeisse, C. Ballif, Nano Lett. 11, $661(2011)$

167. K. Söderström, J. Escarré, O. Cubero, F.-J. Haug, S. Perregaux, C. Ballif, Prog. Photovolt. Res. Appl. 19, 202 (2011)

168. V.E. Ferry, M.A. Verschuuren, H.B.T. Li, R.E.I. Schropp, H.A. Atwater, A. Polman, Appl. Phys. Lett. 95, 183503 (2009)

169. M.-Y. Ke, C.-Y. Wang, L.-Y. Chen, H.-H. Chen, H.-L. Chiang, Y.-W. Cheng, M.-Y. Hsieh, C.-P. Chen, J.J. Huang, IEEE J. Sel. Top. Quantum Electron. 15, 1242 (2009)

170. J.-J. Chen, Y.-K. Su, IEEE Photonics Technol. Lett. 22, $383(2010)$

171. H. Park, K.-J. Byeon, K.-Y. Yang, J.-Y. Cho, H. Lee, Nanotechnology 21, 355304 (2010)

172. S.J. An, J.H. Chae, G.-C. Yi, G.H. Park, Appl. Phys. Lett. 92, 121108 (2008)

173. K.S. Kim, S.-M. Kim, H. Jeong, M.S. Jeong, G.Y. Jung, Adv. Funct. Mater. 20, 1076 (2010)

174. S. Tripathy, S.L. Teo, V.K.X. Lin, M.F. Chen, A. Dadgar, J. Christen, A. Krost, Phys. Status Solidi C 7, 88 (2010)

175. H. Yu, J. Yu, F. Sun, Z. Li, S. Chen, Opt. Commun. 271, $241(2007)$

176. D.-H. Kim, C.-O Cho, Y.-G. Roh, H. Jeon, Y.S. Park, J. Cho, J.S. Im, C. Sone, Y. Park, W.J. Choi, Q-H. Park, Appl. Phys. Lett. 87, 203508 (2005)

177. I.B. Divliansky, A. Shishido, I.-C. Khoo, T.S. Mayer, D. Pena, S. Nishimura, C.D. Keating, T.E. Mallouk, Appl. Phys. Lett. 79, 3392 (2001)

178. S.-I. Na, G.-Y. Ha, D.-S. Han, S.-S. Kim, J.-Y. Kim, J.-H. Lim, D.-J. Kim, K.-I. Min, S.-J. Park, IEEE Photonics Technol. Lett. 18, 1512 (2006)

179. Y. Jung, K.H. Baik, F. Ren, S.J. Pearton, J. Kim, J. Electrochem. Soc. 157, H676 (2010)

180. K.-M. Yoon, K.-Y. Yang, K.-J. Byeon, H. Lee, Solid-State Electron. 54, 484 (2010)

181. S.-H. Lee, K.-J. Byeon, H. Park, J.-Y. Cho, K.-Y. Yang, H. Lee, Microelectron. Eng. 88, 3278 (2011)

182. K.-Y. Yang, S.-C. Oh, J.-Y. Cho, K.-J. Byeon, H. Lee, J. Electrochem. Soc. 157, H1067 (2010)

183. J.-Y. Cho, K.-J. Byeon, H. Park, J. Kim, H.-S. Kim, H. Lee, Nanoscale Res. Lett. 6, 578 (2011)

184. K.-Y. Yang, K.-S. Han, H. Lee, J. Electrochem. Soc. 158, K141 (2011)

185. K.-S. Han, H. Lee, D. Kim, H. Lee, Solar Energy Mater. Solar Cells 93, 1214 (2009)
186. K.-S. Han, J.-H. Shin, H. Lee, Solar Energy Mater. Solar Cells 94, 583 (2010)

187. K.-S. Han, J.-H. Shin, W.-Y. Yoon, H. Lee, Solar Energy Mater. Solar Cells 95, 288 (2011)

188. K.-S. Han, J.-H. Shin, K.-I. Kim, H. Lee, Jpn J. Appl. Phys. 50, 020207 (2011)

189. J.-H. Shin, K.-S. Han, H. Lee, Prog. Photovolt. Res. Appl. 19, 339 (2011)

190. S.-H. Hong, B.-J. Bae, K.-S. Han, E.-J. Hong, H. Lee, K.-W. Choi, Electron. Mater. Lett. 5, 39 (2009)

191. B.-J. Bae, S.-H. Hong, E.-J. Hong, H. Lee, G.-Y. Jung, Jpn J. Appl. Phys. 48, 010207 (2009)

192. S.-H. Lee, K.-S. Han, J.-H. Shin, S.-Y. Hwang, H. Lee, Prog. Photovolt. Res. Appl. (to be published)

193. A. Bessonov, Y. Cho, S.-J. Jung, E.-A. Park, E.-S. Hwang, J.-W. Lee, M. Shin, S. Lee, Solar Energy Mater. Solar Cells 95, 2886 (2011)

194. J. Escarré, C. Battaglia, K. Söderström, C. Pahud, R. Biron, O. Cubero, F.-J. Haug, C. Ballif, J. Opt. 14, 024009 (2012)

195. V.E. Ferry, M.A. Verschuuren, M.C. van Lare, R.E.I. Schropp, H.A. Atwater, A. Polman, Nano Lett. 11, 4239 (2011)

196. H. Spanggaard, F.C. Krebs, Solar Energy Mater. Solar Cells 83, 125 (2004)

197. D. Cheyns, K. Vasseur, C. Rolin, J. Genoe, J. Poortmans, P. Heremans, Nanotechnology 19, 424016 (2008)

198. X. He, F. Gao, G. Tu, D.G. Hasko, S. Hüttner, N.C. Greenham, U. Steiner, R.H. Friend, W.T.S. Huck, Adv. Funct. Mater. 21, 139 (2011)

199. D. Chen, W. Zhao, T.P. Russell, ACS Nano 6, 1479 (2012)

200. P. Thébault, S. Niedermayer, S. Landis, N. Chaix, P. Guenoun, J. Daillant, X. Man, D. Andelman, H. Orland, Adv. Mat. 24, 1952 (2012)

201. X. Man, D. Andelman, H. Orland, P. Thébault, P.-H. Liu, P. Guenoun, J. Daillant, S. Landis, Macromolecules 44, 2206 (2011)

202. S.-M. Park, X. Liang, B.D. Harteneck, T.E. Pick, N. Hiroshiba, Y. Wu, B.A. Helms, D.L. Olynick, ACS Nano 5, $8523(2011)$

203. S. Kim, D.O. Shin, D.-G. Choi, J.-R. Jeong, J.H. Mun, Y.-B. Yang, J.U. Kim, S.O. Kim, J.-H. Jeong, Small 8, $1563(2012)$

204. T. Mårtensson, P. Carlberg, M. Borgström, L. Montelius, W. Seifert, L. Samuelson, Nano Lett. 4, 699 (2004)

205. H. Jeong, K.S. Kim, Y.H. Kim, H. Jeong, H. Song, K.H. Lee, M.S. Jeong, D. Wang, G.Y. Jung, Nanotechnology 22, $275310(2011)$

206. A. Pierret, M. Hocevar, S.L. Diedenhofen, R.E. Algra, E. Vlieg, E.C. Timmering, M.A. Verschuuren, G.W.G. Immink, M.A. Verheijen, E.P.A.M. Bakkers, Nanotechnology 21, 065305 (2010)

207. H. Ko, Z. Zhang, K. Takei, A. Javey, Nanotechnology 21 , 295305 (2010)

Open Access This article is distributed under the terms of the Creative Commons Attribution Noncommercial License which permits any noncommercial use, distribution, and reproduction in any medium, provided the original author(s) and source are credited. 